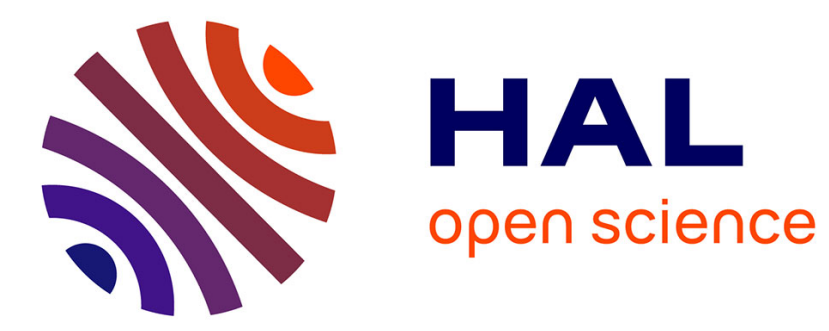

\title{
Spatial risk assessment in case of multiple nuclear release scenarios
}

\author{
Oussama Raboun, Eric Chojnacki, Céline Duffa, David Rios Insua, Alexis
}

Tsoukiàs

\section{- To cite this version:}

Oussama Raboun, Eric Chojnacki, Céline Duffa, David Rios Insua, Alexis Tsoukiàs. Spatial risk assessment in case of multiple nuclear release scenarios. Socio-Economic Planning Sciences, 2020, 70, pp.100721. 10.1016/j.seps.2019.06.006 . hal-02369416

\section{HAL Id: hal-02369416 https://hal.science/hal-02369416}

Submitted on 29 Nov 2020

HAL is a multi-disciplinary open access archive for the deposit and dissemination of scientific research documents, whether they are published or not. The documents may come from teaching and research institutions in France or abroad, or from public or private research centers.
L'archive ouverte pluridisciplinaire HAL, est destinée au dépôt et à la diffusion de documents scientifiques de niveau recherche, publiés ou non, émanant des établissements d'enseignement et de recherche français ou étrangers, des laboratoires publics ou privés.

\section{(1) (1) $\$$}

Distributed under a Creative Commons Attribution - NonCommercial - NoDerivatives| 4.0 


\title{
Spatial risk assessment in case of multiple nuclear release scenarios
}

\author{
Oussama Raboun ${ }^{a, b}$, Eric Chojnacki ${ }^{b}$, Céline Duffa ${ }^{b}$, David Rios Insua ${ }^{c}$, Alexis Tsoukiàs ${ }^{a}$ \\ a Univ. Paris-Dauphine, PSL Research University, CNRS, UMR [7243], LAMSADE, 75016 PARIS, FRANCE \\ ${ }^{b}$ Institut de Radioprotection et de Sureté Nucléaire (IRSN), CADARACHE, FRANCE \\ ${ }^{c}$ Instituto de Ciencias Matemáticas (ICMAT) / CSIC, MADRID, SPAIN
}

\begin{abstract}
This paper presents an approach aimed at assessing multiple criteria spatial risk, where several methods are used for decision aiding purposes, with an application on marine nuclear releases. The case study simulates a post-accident analysis evaluating the impact upon the bay of Toulon of an accidental nuclear release. The problem is characterized by the presence of spatial features, multiple criteria describing the involved assets and uncertainties represented through multiple release scenarios and their corresponding probabilities.
\end{abstract}

Keywords: Multiple criteria decision support, Marine pollution, Environmental risk assessment, Risk rating.

\section{Introduction}

This work is part of a larger project aimed at developing theoretical and practical tools aiding to synthesize multiple criteria spatial risks in case of multiple nuclear release scenarios. A literature review with relevant papers on the integration of multiple criteria decision analysis tools in spatial decision problems until 2006 can be viewed at http://publish.uwo.ca/ jmalczew/list.htm. Despite the existing literature aiming to understand the processes governing the fate of radionuclides in the environment, 1], 2], 3], we note that the concentration of a given isotope is a necessary but not sufficient information for making informed decisions. Let us consider the example of two geographic zones: the first one is characterised by an average concentration level and very important economic and environmental assets while the second one is highly contaminated but does not present any economic or environmental relevance. Clearly, the involved stakeholders will be more sensitive to the impact in the first geographic plot.

Our case study deals with simulated releases from a nuclear submarine at the bay of Toulon, where one of the most important bases of the French Navy is located. In case of a nuclear accident, the incumbent prefect needs synthetic information to support decisions, such as banning certain economic activities, setting a new water management policy at each relevant zone or impeding the access to specific areas. The IRSN 1 is in charge of a project aimed at improving models predicting dispersion and assessing the impact of radionuclides in the environment, see www.irsn.fr/FR/Larecherche/ Organisation/ Programmes/Amorad/Pages/ projetAmorad.aspx\#.W14GxiN7TOQ. In order to provide supplementary post-accident management tools allowing to evaluate environment and economic impacts, we have developed an approach in which data associated to assets involved in the bay are paired with maps displaying the concentration level of a given isotope generating criteria maps. Each map describes the impact of a release concentration for a given criterion. We then use a multiple criteria aggregation procedure generating impact maps taking into account all assets. The final step consists of aggregating uncertain information over release scenarios (release positions, sea conditions,...) through an outranking approach. Our case study serves as a template that can be extended to other release events and geographical areas.

\footnotetext{
${ }^{1}$ Institut de Radioprotection et de Sureté Nucléaire is a French center of expertise and research in radioprotection and safety of nuclear installations. More information can be found at http://www.irsn.fr 
The originality of our work stands on the way we structured and modeled a practical issue, starting from the raw question "How can we evaluate the impact of a nuclear accident, similar to that of Fukushima, in the marine area?" The practical case was offered by the bay of Toulon, due to the presence of nuclear submarines in its port, characterised by the presence of multiple assets and two levels of spatial decomposition. In this paper, we propose the models used to assess the impact of a nuclear release on each asset involved, in case we are interested in identifying the most impacted assets or areas with respect to each asset, as well as to evaluate the global impact taking into account all considered assets.

The paper is organised as follows. Section 2 describes the case study including different decompositions of the area of interest and the associated data. In Section 3, we introduce the main theoretical concepts used in this work. We present in Section 4 the construction procedure of the criteria functions characterizing and evaluating the Bay. In Section 5, we show the results of the multiple criteria aggregation and the aggregation of release scenarios. We end up with a discussion. Several appendices provide additional details about this work and its results.

\section{Case study}

The area of interest is the Bay of Toulon (in what follows, we will use the Bay to refer to it), where a major basis of the French naval force is located, including nuclear submarines, besides being a densely inhabited area with important economic activities. Thus, there is a possibility of major negative impacts in case an accidental nuclear release takes place. Two features are identified in this study:

- Multiple impacts over different assets characterising the Bay.

- Uncertainties relative to accident parameters, to be modeled through scenarios.

In a radioactive release several isotopes may be present such as cesium-137, cesium-134, silver-110 or iodine-131. In our case, we will focus on cesium-137 characterised by a half-life of 30.17 years. However, the developed methodology does not depend on the considered radionuclide.

In our problem context, our objective is to set a decision aiding model based on consequences induced by an accident. The available information includes:

- scientific facts and results: The dispersion model of radionuclides in the marine environment;

- geographic features: Each geographic zone has special characteristics such as the income associated with tourism or fishing;

- norms: Including the maximum allowable levels of concentration for fishing or forbidding an activity.

\subsection{Assets data}

A decomposition of the Bay was carried out within the "Bay contract" by the "Syndicat Intercommunal de l'Aire Toulonnaise" (SIAT, 1998 and 2002). This decomposition was based on the following criteria:

- A physical criterion, relying mainly on the geomorphology and local hydrodynamics of water bodies.

- A biological criterion, taking into account the presence of particular ecosystems.

- A socioeconomic criterion, based upon the presence of certain special activities such as ports and military activities.

In what follows, we adopt the above mentioned division, with seven homogeneous zones illustrated in Figure 1 .

1. The north of the small bay, characterised by maritime and military activities. It includes a military port, freight, passenger transport, boaters and professional fishers.

2. The bay of Lazaret, characterised by aquaculture and tourism activities. 
3. From the beaches Mourillon, Saint-Mandrier, until Cape Brown. The entrance to the small harbour is also characterised by military activity, a port, boaters and maritime transport. Its particularity lies in the fact that it represents a natural area of ecological faunistic and floristic interest, due to the presence of seagrass Posidonia.

4. From zone 3 to "Commune le Pradet". This part is characterised by an important fishing activity, tourism activities and a high presence of seagrass Posidonia.

5. From Cap Sicié to Saint-Elme, characterised by several seaside activities. There is mainly swimming, boating, diving and professional fishing activities. This area is characterised by ecological richness, particularly a high presence of seagrass Posidonia. Moreover, there are three protected zones at "Anse des Sablettes", the "Islands of the Two Brothers" and Cape Sicié.

6. From Marégau Point to Cape Cepet. This area is mainly dedicated to military activities. There is also tourism activities and seagrass Posidonia. This last is an important asset for sea life.

7. The rest of the bay with no land boundary is mainly characterised by professional fishing.

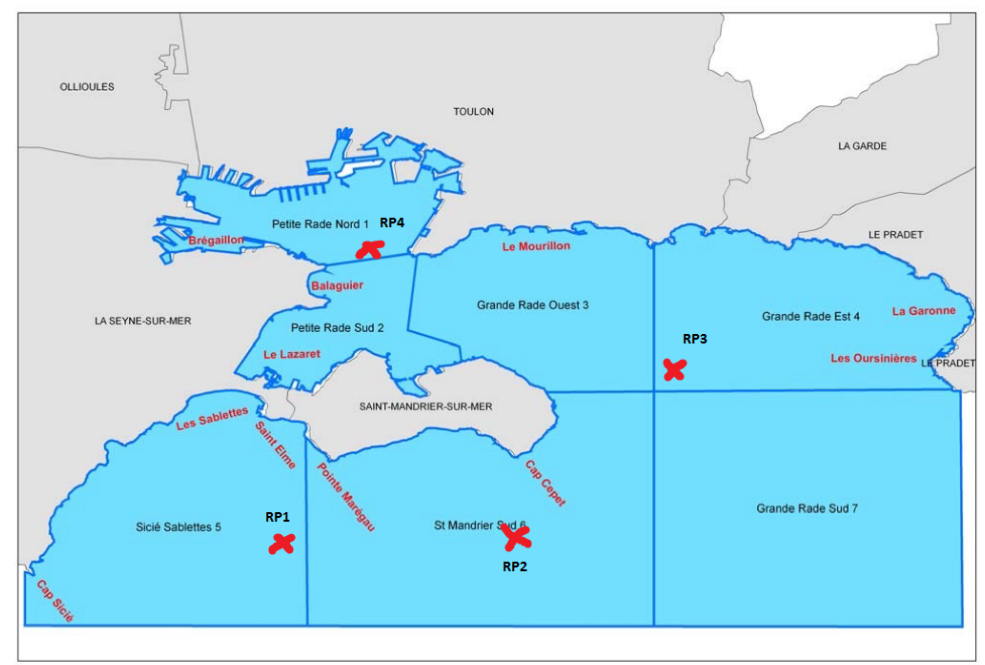

Figure 1: Decomposition of the bay into seven homogeneous zones.

In order to evaluate the consequences of accidents, we distinguished two types of attributes: economic and environmental.

\subsubsection{Economic attributes}

Two types of activities are present in the Bay:

- commercial activities linked with water quality: fishing, water sports, diving, professional fishing and aquaculture;

- Non-commercial activities such as swimming and leisure fishing.

Non-commercial activities seem to be not directly linked with economic assets. However, they have a strong influence over the touristic attractiveness of each zone which might induce an economic impact.

As far as the economic axis is concerned, we shall evaluate the impact of a released cesium- 137 concentration based on three attributes:

- Professional fishing (F), based on an estimation of the annual economic impact of the fish caught. The data comes from the "Système d'Informations Halieutiques" (SIH-2007). Table1 provides the annual turnover associated with professional fishing at each of the zones. 


\begin{tabular}{|c|c|c|c|c|c|c|c|}
\hline Zones & 1 & 2 & 3 & 4 & 5 & 6 & 7 \\
\hline Annual turnover $(\mathrm{k} €)$ & 300 & 300 & 965 & 965 & 934 & 1286 & 1000 \\
\hline
\end{tabular}

Table 1: Annual turnover of professional fishing in 2007.

- Fish farming (FF), supports raising fish and shellfish. The area characterised by this activity is zone 2, representing an important economic asset for Toulon. The main characteristic is that the fish are more impacted by water quality as they cannot swim outside the breeding areas. The turnover generated by this activity in 2007 was $2129(\mathrm{k} €)$.

- Tourist attractiveness (T), refers mainly to swimming, diving and water sports. The economic value of swimming is assessed based on the income of restaurants located at sea shore and accommodations at each municipality. Thus, the value associated with the commune of Toulon will be assigned to zones 1 and 3; that of Seyne-Sur-Mer to zone 2; Pradet to zone 4; and, finally the commune of Saint-Mandrier to zone 6 (zone 7 has no coastline). Data associated with this attribute come from INSEE-Sirene 2007 for the catering sector, Chambre de Commerce et d'Industrie CCI-PACA 2007 for water sports and boaters and BVA-Ifremer 2007 for non professional fishing. Table 2 summarises the turnover associated with touristic activities in the Bay.

\begin{tabular}{|c|c|c|c|c|c|c|c|}
\hline Zones & 1 & 2 & 3 & 4 & 5 & 6 & 7 \\
\hline $\begin{array}{c}\text { Annual turnover } \\
(\mathrm{k} €)\end{array}$ & 34839.5 & 29593 & 20828.5 & 13591.5 & 23113 & 24483 & 1131 \\
\hline
\end{tabular}

Table 2: Annual turnover of Tourism in 2007.

\subsubsection{Environmental axis}

As far as the environmental axis is concerned, we shall focus our attention on the presence of seagrass Posidonia. This is one of the most important ecosystems in Mediterranean coastal zones, playing the same importance as forests in terrestrial areas: It is essential for the preservation of the balance of sea-life, [5], [11, as it:

1. Influences coastal water quality, through significant oxygen production and sediment trapping.

2. Is at the base of many trophic networks, for the production of plant and animal biomass.

3. Plays a fundamental role in the hydrodynamic protection of the coastline and beaches.

4. Fixes sediments and reduces the turbidity of the water, preventing their resuspension during storms.

Data on the mapping of seagrass Posidonia are rare, mostly very old, and its evolutionary dynamics are poorly known. Nevertheless, we have qualitative information on its presence at each geographic zone. Table 3 summarises its presence in the Bay.

\begin{tabular}{|c|c|c|c|c|c|c|c|}
\hline Zones & 1 & 2 & 3 & 4 & 5 & 6 & 7 \\
\hline $\begin{array}{c}\text { Degree of the } \\
\text { presence of seagrass } \\
\text { Posidonia }\end{array}$ & Absent & Absent & Average & High & High & High & Absent \\
\hline
\end{tabular}

Table 3: Presence of seagrass Posidonia in the Bay (2002).

Cesium concentration might be included as a relevant environmental indicator representing water quality. However, we will not consider it independently, since we use it to assess criteria and we are interested in its impact on assets characterising the bay. 
We modeled uncertainty about the accident parameters through representative scenarios. We shall consider three sea conditions with their associated probabilities, as described in Table 4 and four initial release

\begin{tabular}{|c|l|l|}
\hline Scenario & Prevailing wind & Probability \\
\hline$\beta_{1}$ & Mistral & $q_{1}$ \\
\hline$\beta_{2}$ & East & $q_{2}$ \\
\hline$\beta_{3}$ & Steady & $q_{3}$ \\
\hline
\end{tabular}

Table 4: Discretisation of sea conditions.

positions with their associated probabilities, as specified in Table 5 displayed by red crosses in Figure 1 .

\begin{tabular}{|c|c|c|}
\hline Position in the map & Scenarios & Probability \\
\hline Zone 5 & $R P_{1}=(43.053,5.89)$ & $r_{1}$ \\
\hline Zone 6 & $R P_{2}=(43.053,5.96)$ & $r_{2}$ \\
\hline Zone 4 & $R P_{3}=(43.079,5.975)$ & $r_{3}$ \\
\hline Zone 1 & $R P_{4}=(43.103,5.918)$ & $r_{4}$ \\
\hline
\end{tabular}

Table 5: Discretisation of initial release positions.

\subsection{Generating concentration data}

Many studies have been conducted to model the physical dispersion process of radioactive substances in . e.g. [1, 2, 3, 9$], 8,[13$. These have led to the development of simulation tools, such as STERNE ${ }^{2}$ which we have used in our case study. The input parameters required by this tool are

\subsubsection{Sources of uncertainty}

Since accidental nuclear releases are related with the routes undertaken by the submarines, there will be

- The sea conditions (wind, currents, ...), at the time of the release, identified by a parameter $\beta$. In the case of Toulon, they are dominated by wind [13, and their probabilities can be estimated using a meteorologic database.

- The position $R P=\left(x_{R P}, y_{R P}\right)$ where the release takes place, being, respectively, the latitude and longitude. We identify the main typical routes for submarines with some uncertainty around them.

The corresponding probabilities will be assessed in Section 5.2 where we shall synthesise the twelve scenarios.

\subsubsection{Assessing cesium concentration}

The approach proposed here is driven by the contaminant concentration at each plot of the bay. This, in turn, will be driven by the amount initially released as well as the release position $R P$ and sea conditions $\beta$. Based on a hydrodynamic model [8] sketched in Appendix A, we may estimate the concentration of the radioactive substance in water (respectively in a marine organism) at any point $z=(x, y)$ in the map, which we designate $c_{w}(z, R P, \beta)$ (respectively $\left.c_{o}(z, R P, \beta)\right)$.

STERNE offers the possibility of using tracking points to simulate the concentration evolution of a given isotope. We discretised the bay into several geographic units, represented by their tracking points in the center. The previous decomposition of the Bay in 7 homogeneous zones was too rough to be applied for

\footnotetext{
${ }^{2}$ Simulation du Transport et du transfert d'Eléments Radioactifs dans l'environNEment marin, translated as Simulation of radionuclide transport and transfer in marine environments

${ }^{3}$ The amount initially released can be also considered as a source of uncertainty. However, in this work we shall fix it to $10^{15} \mathrm{~Bq}$, i.e. a very important release.
} 
the estimation of the contaminant concentration, as it may lead to missing significant concentrations. We instead defined 97 geographical units adjusted to the map of the Bay. Each geographic unit is defined by two representative points: a tracking point at the bottom of the sea and another one at $1 \mathrm{~m}$ depth. The reasons for choosing two depth levels are related with the nature of the chosen attributes. In what follows, we shall use "geographic zone" to refer to the first decomposition in 7 zones and "geographic units" to the second decomposition, in 97 units. Figure 2 displays 10 evolution curves of cesium concentration at $1 \mathrm{~m}$ depth at the 10 most contaminated zones based on the maximum concentration attained.

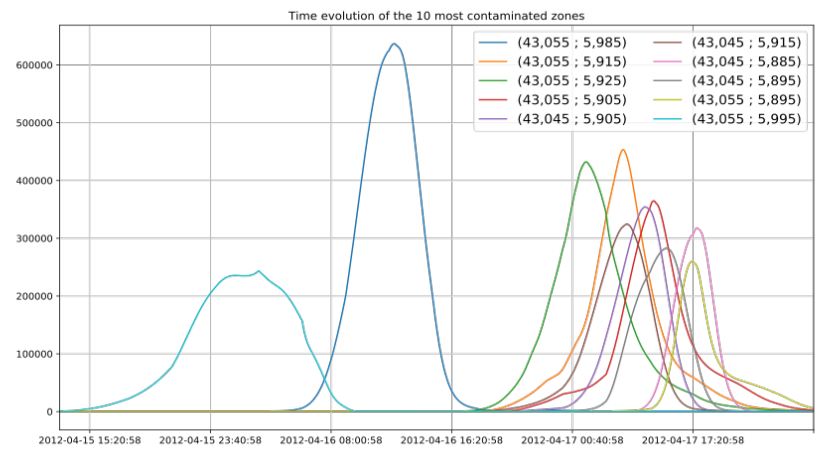

Figure 2: 10 highest evolutions of cesium concentration in water over time.

We summarize the concentration evolution curves through their mean and maximum values. Figures 3 and 4 display, respectively, the maximum and mean values corresponding to tracking points at $1 \mathrm{~m}$ depth for the release scenario (mistral; $R P_{2}$ ).

\begin{tabular}{|c|c|c|c|c|c|c|c|c|c|c|c|c|c|c|c|c|}
\hline & $5,86,5,87$ & $5,87,5,88$ & $5,88,5,89$ & $5,89,5,9$ & $5,9,5,91$ & $5,91,5,92$ & $5,92,5,93$ & $5,93,5,94$ & $5,94,5,95$ & $5,955,5,96$ & $5,96,5,97$ & $5,97,5,98$ & $5,98 \_5,99$ & 5,996 & $66,6,01$ & $6,016,6,02$ \\
\hline 43,11 43,12 & & & $3,09 E-10$ & $1,09 E-09$ & $3,53 \mathrm{E}-08$ & $4,87 E-07$ & $1,4 \mathrm{AE}-04$ & & & & & & & & & \\
\hline $43,1,43,11$ & & & $2,09 \mathrm{E}-09$ & $1,09 E-08$ & $2,63 \mathrm{E}-06$ & 7,85E-05 & $1,00 E+00$ & $3,24 E+01$ & $4,52 E+01$ & $6,54 E+01$ & $7,77 \mathrm{E}+01$ & $5,84 E+01$ & $9,02 E+01$ & $1,55 E+03$ & $2,89 E+03$ & \\
\hline $43,09,43,1$ & & & & & & $3,23 \mathrm{E}-03$ & $4,62 E+00$ & $3,35 E+01$ & $6,63 E+01$ & $4,34 E+01$ & $5,29 E+01$ & $2,24 E+02$ & $1,02 E+03$ & $1,80 E+03$ & $7,72 E+03$ & $1,51 E+04$ \\
\hline $43,08 \_43,09$ & & & & & $2,66 E-03$ & $6,13 E-02$ & $1,14 E+00$ & $3,46 E+01$ & $2,50 E+01$ & $8,36 E+01$ & $6,50 E+02$ & $4,14 E+03$ & $8,56 E+03$ & $3,58 E+104$ & $7,31 E+04$ & $8,42 E+04$ \\
\hline $43,07,43,08$ & & & $1,45 E+03$ & $1,25 E+03$ & & & & & & $2,39 E+04$ & $1,07 E+04$ & $2,95 \mathrm{E}+04$ & $1,54 E+05$ & $2,55 E+05$ & $2,45 E+05$ & $1,70 E+05$ \\
\hline $43,06 \_43,07$ & & $3,42 E+03$ & $2,00 E+03$ & $5,21 E+03$ & $2,82 E+04$ & $6,96 \mathrm{E}+04$ & $8,04 E+04$ & $3,96 E+05$ & $9,64 E+05$ & $6,84 E+04$ & $1,10 E+05$ & $1,55 E+05$ & $3,07 E+05$ & $4,11 E+05$ & 4,05E+05 & $3,37 E+05$ \\
\hline $43,05_{-} 43,06$ & $2,75 E+03$ & $8,86 E+02$ & $1,71 \mathrm{E}+03$ & $4,38 E+03$ & $1,20 E+04$ & $2,09 E+04$ & $1,30 E+05$ & $3,62 E+05$ & $3,30 E+05$ & $1,87 E+05$ & $1,73 E+05$ & $2,59 E+05$ & $1,09 E+05$ & $1,85 E+05$ & $3,31 E+05$ & $1,85 E+05$ \\
\hline $43,04 \_43,05$ & $2,01 E+03$ & $1,64 E+03$ & 4,06E+03 & $3,53 E+03$ & $2,06 E+04$ & $2,48 E+04$ & 4,51E+04 & $9,23 E+04$ & $2,56 E+05$ & $2,61 E+05$ & $7,11 E+04$ & $4,92 E+04$ & $5,74 E+04$ & $1,39 E+05$ & $1,08 E+05$ & $1,61 E+07$ \\
\hline
\end{tabular}

Figure 3: Maximum concentration, $1 \mathrm{~m}$ depth, at the 97 geographic units for (mistral; $\left.R P_{2}\right)$.

Empty cells in both figures correspond to land space. In all simulations we face a factor of 10 between the average and maximum values. We aggregate both values and move from a cardinal to an ordinal scale by assigning each zone to a corresponding concentration level. This can be achieved in several ways depending on the eventual compensation between both values. In our work we considered a geometric mean between them as their is a scale factor between both values. Figure 5 illustrates their aggregation considering the same level of importance for both evaluations at each zone.

A colour coding will reflect the contamination level at each geographic unit. We consider 5 levels from less to more contaminated. The cutting levels are fixed based on expert judgment. Level 1 is displayed in blue, 2 in green, 3 in yellow, 4 in orange and 5 in red. We shall use this grading colour in the rest of the paper. As a first way to display the information, we could present the map $\left(z, c_{w}(z, R P, \beta)\right)$, which provides, for each geographic unit $z$, the estimated contamination level, in an ordinal scale, given specific initial conditions. 


\begin{tabular}{|c|c|c|c|c|c|c|c|c|c|c|c|c|c|c|c|c|}
\hline & $5,86 \_5,87$ & $5,87,5,88$ & $5,88,5,89$ & $5,89,5,9$ & $5,95,91$ & $5,91,5,92$ & $5,92,5,93$ & $5,93,5,94$ & $5,94 \_5,95$ & $5,95 \_5,96$ & $5,96 \_5,97$ & $5,97,5,98$ & $5,98 \_5,99$ & 5,996 & 66,01 & $6,016,02$ \\
\hline $43,11433,12$ & & & $1,27 E-12$ & 2. $3,75 E-11$ & 1,35E-09 & $9 \quad 2,08 E-08$ & 4,21E- 06 & & & & & & & & & \\
\hline $43,1 \_43,11$ & & & $3,24 E-11$ & $4,24 E-10$ & $\quad 1,82 E-07$ & $6,21 E-06$ & $3,05 E-02$ & 2. $3,00 E+00$ & $5,59 E+00$ & $8,53 E+00$ & 9, $\quad$, $55 E+00$ & $7,28 E+00$ & $1,31 E+01$ & $1,31 E+02$ & $3,19 E+02$ & \\
\hline $43,09 \_43,1$ & & & & & & $2,35 E-04$ & $1,67 E-01$ & 1. $5,13 E+00$ & $1,18 E+01$ & $7,32 E+00$ & $9,17 €+00$ & $1,98 E+01$ & $7,05 E+01$ & $1,92 E+02$ & $4,07 E+02$ & $1,155+03$ \\
\hline 43,08 _33,09 & & & & & $1,47 E-04$ & $1,88 E-03$ & $5,47 E-02$ & $5,376+00$ & $4,46 E+00$ & $6,85 E+00$ & 5, 5,45E+01 & $2,81 E+02$ & $8,48 E+02$ & $1,99 E+03$ & $3,42 E+03$ & $5,99 E+03$ \\
\hline 43,07 _ 43,08 & & & $2,10 E+02$ & $1,91 E+02$ & & & & & & $1,22 E+03$ & $8,22 E+02$ & $2,41 E+03$ & $1,25 E+04$ & $2,77 E+04$ & $2,55 E+04$ & $1,90 E+04$ \\
\hline 43,06 _43,07 & & $4,56 E+02$ & $2 \quad 2,79 E+02$ & 2. $6906+02$ & $3,80 E+03$ & $3 \quad 7,25 E+03$ & $4,50 E+03$ & 3. $1,98 E+04$ & $4,37 E+04$ & $5,73 E+03$ & $9,49 E+03$ & $1,72 E+04$ & $3,85 E+04$ & $4 \quad 4,05 E+04$ & $3,79 E+04$ & $2,74 E+04$ \\
\hline $43,05 \_43,06$ & $4,32 E+02$ & $1,42 E+02$ & $2 \quad 2,52 E+02$ & 2. $5,93 E+02$ & $1,76 E+03$ & $3 \quad 2,58 E+03$ & $3 \quad 6,92 E+03$ & $2,11 E+04$ & $1,56 \mathrm{E}+04$ & $1,35 E+04$ & $1,64 E+04$ & $2,50 \mathrm{E}+04$ & $1,08 E+04$ & $4 \quad 1,95 E+04$ & $2,70 E+04$ & $1,36 E+04$ \\
\hline $43,04 \_43,05$ & $3,76 E+02$ & $3,69 E+02$ & $2 \quad 5,58 E+02$ & $7,996+02$ & $1,85 E+03$ & $3 \quad 2,95 E+03$ & $4,19 E+03$ & $5,82 E+03$ & $1,15 E+04$ & $1,31 E+04$ & $4,72 E+03$ & $3,45 E+03$ & $3,16 E+03$ & $3 \quad 8,44 E+03$ & $3 \quad 9,61 E+03$ & $1,57 \mathrm{E}+05$ \\
\hline
\end{tabular}

Figure 4: Average concentration, $1 \mathrm{~m}$ depth, at the 97 geographic units for (mistral; $\left.R P_{2}\right)$.

\begin{tabular}{|c|c|c|c|c|c|c|c|c|c|c|c|c|c|c|c|c|}
\hline Csw & $5,86 \_5,87$ & $5,87 \_5,88$ & $5,88 \_5,89$ & $5,89 \_5,9$ & $5,90 \_5,91$ & $5,91 \_5,92$ & $5,92 \_5,93$ & $5,93 \_5,94$ & $5,94 \_5,95$ & $5,95 \_5,96$ & $5,95 \_5,97$ & $5,97 \_5,98$ & $5,98 \_5,99$ & $5,99 \_6$ & $6 \_6,01$ & $6,01 \_6,02$ \\
\hline $43,11 \_43,12$ & & & $3,44 E-10$ & $1,13 \mathrm{E}-09$ & $3,67 \mathrm{E}-08$ & $5,08 \mathrm{E}-07$ & $1,48 \mathrm{E}-04$ & & & & & & & & & \\
\hline $43,1 \_43,11$ & & & $2,79 \mathrm{E}-09$ & 1,13E-08 & $2,82 \mathrm{E}-06$ & $8,47 E-05$ & $1,03 E+00$ & $3,54 \mathrm{E}+01$ & $5,08 \mathrm{E}+01$ & $7,39 \mathrm{E}+01$ & $8,73 E+01$ & $6,57 E+01$ & $1,03 E+02$ & $1,68 \mathrm{E}+03$ & $3,21 \mathrm{E}+03$ & \\
\hline 43,09_43,1 & & & & & & 3,47E-03 & $4,78 E+00$ & $3,87 E+01$ & $7,82 \mathrm{E}+01$ & $5,08 E+01$ & $6,21 E+01$ & $2,44 E+02$ & $1,09 E+03$ & $1,99 E+03$ & $8,13 E+03$ & $1,62 E+04$ \\
\hline $43,08 \_43,09$ & & & & & $2,81 \mathrm{E}-03$ & $6,32 E-02$ & $1,20 E+00$ & $4,00 E+01$ & $2,94 E+01$ & $9,04 E+01$ & $7,05 E+02$ & $4,42 E+03$ & $9,40 E+03$ & $3,78 E+04$ & $7,65 E+04$ & $9,01 E+04$ \\
\hline $43,07 \_43,08$ & & & $1,66 E+04$ & $1,45 E+04$ & & & & & & $2,51 \mathrm{E}+04$ & $1,15 E+04$ & $3,19 E+04$ & $1,67 E+05$ & $2,83 E+05$ & $2,70 \mathrm{E}+05$ & $1,89 \mathrm{E}+05$ \\
\hline $43,06 \_43,07$ & & $3,87 E+03$ & $2,28 E+03$ & $5,90 E+03$ & $3,20 E+04$ & $7,69 E+04$ & $8,49 E+04$ & 4,16 & & $7,41 E+04$ & $1,20 E+05$ & $1,72 E+05$ & $3,45 E+05$ & $4,51 E+05$ & $4,43 E+05$ & $3,64 E+05$ \\
\hline $43,05 \_43,06$ & $3,18 E+03$ & $1,03 E+03$ & $1,97 \mathrm{E}+03$ & $4,98 E+03$ & $1,38 E+04$ & $2,35 E+04$ & $1,37 E+05$ & $3,83 E+05$ & $3,45 E+05$ & $2,01 E+05$ & $1,90 E+05$ & $2,84 \mathrm{E}+05$ & $1,20 E+05$ & $2,04 E+05$ & $3,58 E+05$ & $1,99 \mathrm{E}+05$ \\
\hline $43,04 \_43,05$ & $2,39 E+03$ & $2,01 E+03$ & $4,62 E+03$ & $4,33 E+03$ & $2,24 E+04$ & $2,78 E+04$ & $4,93 E+04$ & $9,81 E+04$ & $2,67 E+05$ & $2,74 E+05$ & $7,59 E+04$ & $5,26 E+04$ & $6,05 E+04$ & $1,47 E+05$ & $1,18 E+05$ & $1,63 E+07$ \\
\hline
\end{tabular}

Figure 5: Contamination level for 97 geographic units for (mistral; $R P_{2}$ ).

Figure 6 displays the contamination level induced by the release scenario (mistral; $R P_{2}$ ) using the previous colour code.

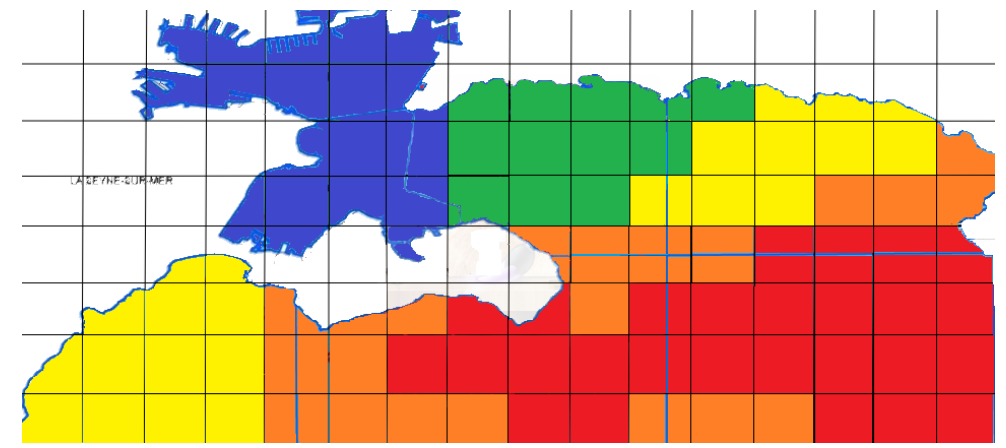

Figure 6: Map displaying the contamination level corresponding to (mistral; $\left.R P_{2}\right)$.

\section{Multiple criteria decision analysis}

In Section 2.1. we described the Bay of Toulon as a rich area where several assets are involved and can be impacted in case of a nuclear release. Our first objective is to define functions, which we shall call criteria, allowing us to assess the impact on each asset at each geographic unit. Each function evaluates a geographic unit from a single perspective. In consequence, we shall associate with each criterion a map evaluating the impact on the corresponding asset 4 . We shall consider the four criteria expressed on an ordinal scale, see section 4, all of which need to be taken into account in an appropriate multiple criteria formulation.

\footnotetext{
${ }^{4}$ Considering each criterion function separately, we can either identify the most impacted geographic units or compute the expected impact.
} 
The field of multiple criteria decision analysis (MCDA) offers a set of operational tools and methodologies to incorporate the decision maker's preferences as well as any information allowing the decision analyst to evaluate a set of actions described by multiple attributes. In real-world cases, several problem statements can be considered referring to the way in which decision aiding is envisaged, see [18]:

- clustering (partition the set of alternatives into unordered not pre-defined equivalence classes; the clusters).

- assignment (partition the set of alternatives into unordered pre-defined equivalence classes).

- rating (partition the set of alternatives into ordered pre-defined equivalence classes).

- ranking (partition the set of alternatives into ordered not pre-defined equivalence classes).

Modeling a MCDA problem requires representing preferences either measuring their values, as in the case of multi-attribute value theory, or directly using binary relations, as in the case of social choice theory and outranking based methods, see [4].

In our case, we aim at assigning each geographic unit to the corresponding impact level. We consider five predefined and ordered impact categories $C_{1}, \ldots, C_{5}$, ranked from best to worst $C_{h} \gg C_{h+1} \forall h \in\{1, \ldots, 4\}$ where $\gg$ refers to a complete order on the set of categories. Hence, the type of decision aid required here is a rating problem statement.

Two main methods corresponding to two different approaches deal with rating problems: UTADIS and ELECTRE-TRI. The UTADIS method was first presented in [6], being a variant of the well-known UTA method [12. UTADIS consists of defining a marginal utility function over criteria, taking respectively the value 0 and 1 for the least and most preferred values of each criterion, and evaluating each action with an additive utility function. Such methods are suitable in multiple criteria problems where trade-offs among criteria are possible and meaningful. Alternatively, the ELECTRE-TRI method is an outranking based procedure first introduced in [19]. This method uses a majority rule, while respecting a minority using a veto rule, to compare the actions to the profiles characterizing categories; ELECTRE-TRI method is detailed in Appendix B. The MCDA procedure used in this work is based on ELECTRE-TRI, as trade-offs among the criteria were not interpretable.

\section{Construction of criteria}

The multiple criteria problem at hand adopts a rating formulation in which we consider the four criteria reflected in Table 6, with scales referring to the raw impact of a nuclear accident at each geographic unit. All criteria considered to evaluate the Bay are based on water quality through the concentration of cesium in water. Hence, the criteria will measure the impact of a given concentration on the assets involved at each geographic zone.

\begin{tabular}{|l|l|l|}
\hline & Criteria & scale \\
\hline 1 & Fishing & impact level \\
\hline 2 & Fish Farming & impact level \\
\hline 3 & Seagrass Posidonia & Impact level \\
\hline 4 & Tourism & impact level \\
\hline
\end{tabular}

Table 6: Criteria and scales.

We start by presenting the typology of impact functions, allowing to associate with each concentration level an impact on an asset. For example, given a concentration level, the impact function will assess the proportion of tourists giving up visiting a geographic unit, the proportion of fishes not allowed to be commercialised or the impact on seagrass Posidonia. In the second part of this section, we construct the criteria functions, taking into account the impact function and the data associated with the assets. For instance, the tourism criterion is evaluated based on the income in a geographic zone, when there is no 


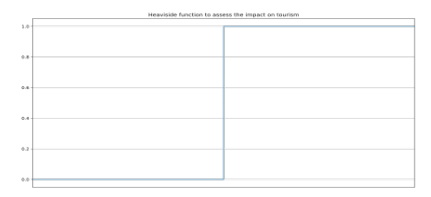

Figure 7: Heaviside impact function.

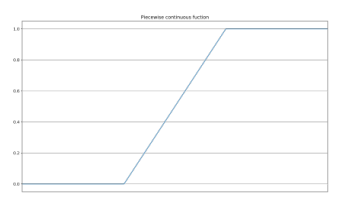

Figure 8: Linear impact function.

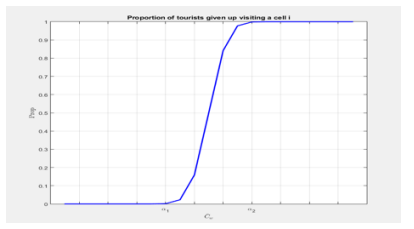

Figure 9: Cumulative impact function.

accident, multiplied by the proportion of tourists giving up visiting the such unit given a concentration level

\subsection{Typology of impact functions}

We aim now at evaluating the impact of a given level of contamination on each asset. The considered

- independent geographic units. As units are small, we do not consider mutual influences between neighbouring units. Thus, the impact on a geographic unit will only depend on its concentration level.

- The impact function does not depend on geographic units, as it depends on the characteristics of the assets.

Three types of impact functions will be considered. The choice of them will depend on the characteristics

- Heaviside function: We consider that a given asset is impacted from a certain level of concentration. This function is used in evaluating the impact on seagrass Posidonia.

- Linear function: no impact is considered before a first threshold is met while an important impact is assumed after the second one. Between both thresholds, the impact is linear. This type of function can be chosen when the population response is linearly proportional to pollution levels.

- Cumulative function: It is more suitable for modeling social phenomena for which the number of people influencing the evaluation of areas is important. We will use this function to assess the impact on tourism and fishing.

The cumulative impact function requires calibration reflecting the impact of different levels of concentration on a given asset. For example, qualitatively, the higher the concentration, the less tourists will visit the corresponding polluted area. This function can be derived through a weighted sum of linear functions, of type 2, representing each the impact assessment by a pool of experts, assessing a "tolerance threshold" and a "reaction threshold". Alternatively, we can calibrate the median for each contamination level as we do here. This approach is inspired by the probability equivalent method for assessing utilities [10]. Let us call the cumulative impact function $\operatorname{prop}_{i}\left(c_{k}\right)$, where $i$ refers to a geographic unit $i$ and $c_{k}$ is the level of contamination in the marine organism $k=o$ or in seawater $k=w$. Our objective is to find for a few concentrations $c_{k_{1}}, \ldots, c_{k_{5}}{ }^{5}$ the corresponding $\operatorname{prop}_{i}\left(c_{k_{1}}\right), \ldots, \operatorname{prop}_{i}\left(c_{k_{5}}\right)$, through expert judgment, and then adjust a curve. Note that $\operatorname{prop}_{i}\left(c_{k}\right)$ will essentially be uncertain and we shall focus on assessing its median using lottery comparison.

In what follows we apply this approach to the attribute Tourism and thus $k=w$. For this we compare two lotteries:

- Lottery $A$, represents throwing a fair coin in which the expert wins $100 €$ if he obtains Head and $0 €$ is he obtains "Tail". This serves as reference.

${ }^{5} 5$ represents the number of contamination levels introduced in Section 2.2 .2 
- Lottery $B$, represents the calibrated event and gives the expert $100 €$ if prop $\geq q$ and $0 €$ otherwise, where $\operatorname{prop}=\operatorname{prop}_{i}\left(c_{w}\right)$ is the proportion of tourists giving up visiting a geographic unit in case $c_{w}$ is high enough and $q$ is the calibrating value.

We ask the expert whether he prefers $A$ to $B(A \succeq B)$. In such case, we have: $100 \times \frac{1}{2}+0 \times \frac{1}{2} \geq$ $100 \times P($ prop $\geq q)+0 \times(1-P($ prop $\geq q))$; we need to adjust $q$ to approximate the median. For this, we can design an iterative procedure to converge to it, bounding it from below and above. Initially, the bounding interval is $[0,1]$ and we iteratively split it depending on the responses of the expert. Specifically, we use $q=\frac{Y+X}{2}$, for $[X, Y]$ and adjust $X$ and $Y$ according to expert responses, with $X=0, Y=1$ initially. For a large number of iterations this will converge to the median. Figure 10 displays the calibration for a few concentration levels using the above procedure. The same approach remains valid for the fishing attribute, for which $k=o$.

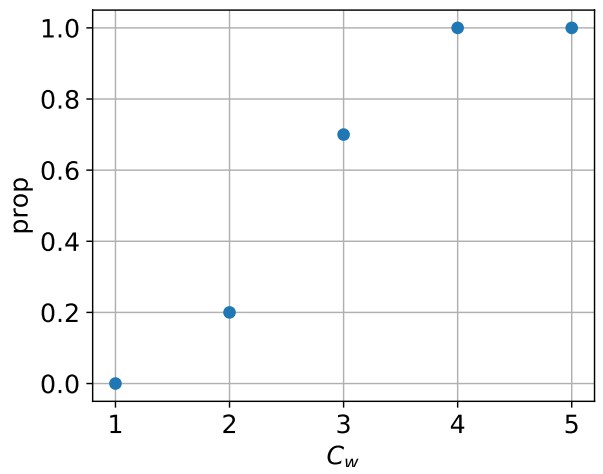

Figure 10: Calibration of proportion of tourists giving up visiting a cell.

\subsection{Tourism}

We construct first the criterion function for tourism, referring to the level of economic loss related with the tourism sector. This last is assessed as $\operatorname{prop}_{i}\left(c_{w}\left(z_{i}, s\right), T\right) \operatorname{Inc}_{i}(T)$ where $\operatorname{prop}_{i}\left(c_{w}\left(z_{i}, s\right), T\right)$ represents the proportion of tourists refraining from visiting the geographic unit $i$ under the incumbent release scenario and $\operatorname{Inc}_{i}(T)$ represents the income associated with the geographic unit $i$. The function $\operatorname{prop}_{i}\left(c_{w}\left(z_{i}, s\right), T\right)$ has been assessed in section 4.1. Figure 10

In order to evaluate the economic importance of each geographic unit, an issue with the spatial decomposition arises:

- Data associated with tourism revenues are available just for the seven geographic zones. We partitioned the annual turnover proportionally between all geographic units constituting each of the seven geographic zones.

- Some geographic units are shared between several homogeneous zones. The solution adopted is to evaluate the geographic units by considering the turnover proportionally to the surface occupied by geographic zones at the geographic unit. This entails the use of the same decomposition as for cesium concentration simulations.

Thus, the estimated annual turnover at each geographic unit is

$$
\operatorname{Inc}_{i}(T)=\sum_{j \in Z, s t: Z \cap\{i\} \neq \emptyset} \frac{S_{i j}}{\sum_{i \in U \cup Z} S_{i j}} \operatorname{Tur}_{j}(T),
$$


where $U$ and $Z$ represent, respectively, the set of geographic units (decomposition of the Bay adopted to forecast cesium concentration) and the set of geographic zones (decomposition made to describe the attributes); $T$ refers to the asset Tourism; $S_{i j}$ the maritime surface (land excluded) belonging both to the geographic unit $i$ of $U$ and the zone $j$ of $Z ; \operatorname{Tur}_{j}(T)$ the turnover associated with geographic zone $j$.

We denote by $g_{T}(i, s)$, the function of the tourism criterion rating the geographical unit $i$, given a scenario $s$. Such function would be 6 .

$$
g_{T}(i, s)=\left\{\begin{array}{l}
1, \text { if } \operatorname{prop}_{i}\left(c_{w}\left(z_{i}, s\right), T\right) \operatorname{Inc} c_{i}(T) \times 97<10^{4} \\
2, \text { if } 10^{4} \leq \operatorname{prop}_{i}\left(c_{w}\left(z_{i}, s\right), T\right) \operatorname{Inc}_{i}(T) \times 97<10^{6} \\
3, \text { if } 10^{6} \leq \operatorname{prop}_{i}\left(c_{w}\left(z_{i}, s\right), T\right) \operatorname{Inc}_{i}(T) \times 97<10^{7} \\
4, \text { if } 10^{7} \leq \operatorname{prop}_{i}\left(c_{w}\left(z_{i}, s\right), T\right) \operatorname{Inc}_{i}(T) \times 97<10^{8} \\
5, \text { if } 10^{8} \leq \operatorname{prop}_{i}\left(c_{w}\left(z_{i}, s\right), T\right) \operatorname{Inc}_{i}(T) \times 97
\end{array}\right.
$$

where $10^{4}, 10^{6}, 10^{7}, 10^{8}$ represent the economic losses delimiting each impact category. The cutting thresholds used in the different criteria are assessed based on expert judgment. Figure 11 shows the assessment of the tourism criterion for the mistral-type marine currents and release point $R P_{2}$.

\begin{tabular}{|c|c|c|c|c|c|c|c|c|c|c|c|c|c|c|c|c|}
\hline Tourism & $5,86 \_5,87$ & $5,87 \_5,88$ & $5,88 \_5,89$ & $5,89 \_5,9$ & $5,90 \_5,91$ & $5,91 \_5,92$ & $5,92 \_5,93$ & $5,93 \_5,94$ & 5,94 _5,95 & $5,95 \_5,96$ & $5,95 \_5,97$ & $5,97 \_5,98$ & $5,98 \_5,99$ & $5,99 \_6$ & $6-6,01$ & $6,01 \_6,02$ \\
\hline 43,11_43,12 & & & 1 & 1 & 1 & 1 & 1 & & & & & & & & & \\
\hline 43,1_43,11 & & & 1 & 1 & 1 & 1 & 1 & 3 & 3 & 3 & 3 & 3 & 4 & 4 & 4 & \\
\hline 43,09_43,1 & & & & & & 1 & 1 & 3 & 3 & 3 & 3 & 4 & 4 & 4 & 4 & 5 \\
\hline $43,08 \_43,09$ & & & & & 1 & 1 & 1 & 3 & 3 & 3 & 3 & 4 & 4 & 5 & 5 & 5 \\
\hline $43,07 \_43,08$ & & & 4 & 4 & & & & & & 5 & 5 & 5 & 5 & 5 & 5 & 5 \\
\hline $43,06 \_43,07$ & & 4 & 4 & 4 & 5 & 5 & 5 & 5 & 5 & 5 & 5 & 5 & 5 & 5 & 5 & 5 \\
\hline $43,05 \_43,06$ & 4 & 4 & 4 & 4 & 5 & 5 & 5 & 5 & 5 & 5 & 5 & 5 & 5 & 5 & 5 & 5 \\
\hline $43,04 \quad 43,05$ & 4 & 4 & 4 & 4 & 5 & 5 & 5 & 5 & 5 & 5 & 5 & 5 & 5 & 5 & 5 & 5 \\
\hline
\end{tabular}

Figure 11: evaluation of the tourism criterion under the scenario (Mistral, $R P_{2}$ )

We can display the above results through maps 7 . As an example, the map in Table 7 represents the impact on the tourism criterion under scenario (Mistral, $R P_{2}$ ). Results corresponding to the other scenarios can be found in the supplementary material.

$R P_{1}$

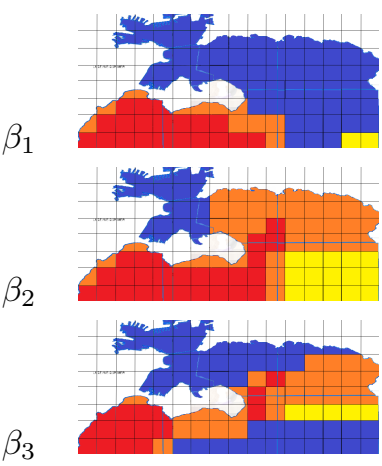

$R P_{2}$

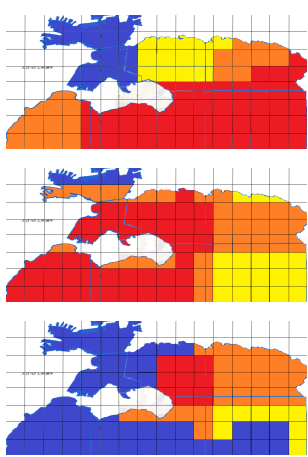

$R P_{3}$

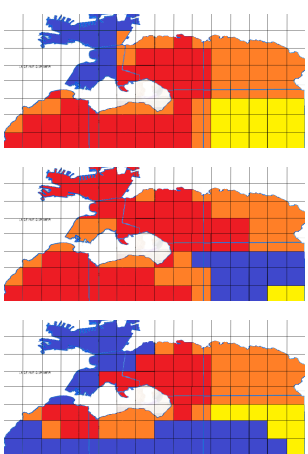

$R P_{4}$

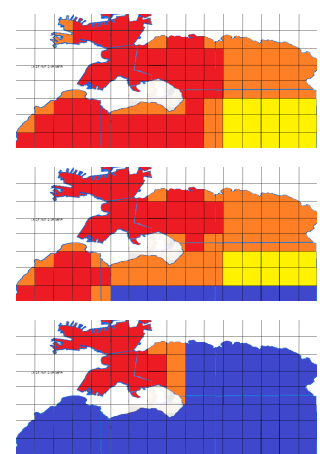

Table 7: Tourism criterion maps for the twelve scenarios

Some relevant information can be assessed in this way. For example we can identify areas which are most at risk from the perspective of tourism. (e.g. the red ones)

\footnotetext{
${ }^{6} 97$ in the criterion function refers to the number of geographic units

${ }^{7}$ We used the same colour coding as in Figure 6
} 
The economic loss in the bay associated with scenario $s=\left(\beta_{h}, R P_{k}\right)$ can be obtained through spatial aggregation, without considering interactions between neighbouring geographic units based on:

$$
\sum_{i} \operatorname{prop}_{i}\left(c_{w}\left(z_{i}, \beta_{h}, R P_{k}\right), T\right) \operatorname{Inc}_{i}(T)
$$

The expected economic loss in the whole area, through aggregating uncertainties over initial conditions, $s=\left(\beta_{h}, R P_{k}\right)$, would be: e

$$
\varphi_{T A}=\sum_{i} \operatorname{Inc}_{i}(T) \sum_{h=1}^{3} \sum_{k=1}^{4} \operatorname{prop}_{i}\left(c_{w}\left(z_{i},\left(\beta_{h}, R P_{k}\right), T\right) q_{h} r_{k},\right.
$$

which we denote $\varphi_{T A}=\sum \operatorname{Inc}_{i}(T) \operatorname{prop}_{i}\left(c_{w}, T\right)$.

The expected income in tourism sector when there is no accident would be:

$$
\varphi_{T}=\sum_{i} \operatorname{Inc} c_{i}(T),
$$

Then, the expected income on the whole area after an accidental release would be:

$$
\varphi_{T}-\varphi_{T A} .
$$

We could also use relative losses. For example, for the income from tourism, it would be:

$$
\frac{\varphi_{T A}}{\varphi_{T}} .
$$

All these indices, derived from the process of the construction of the tourism criterion may help the decision maker assessing the impact of an eventual accident over the tourism sector.

\subsection{Fishing}

We assess now the fishing criterion function, focusing on the economic loss on the fishing sector at each geographic unit. Such loss is evaluated by coupling the proportion of fish not authorised for sale and the economic income before the accident in a geographic unit. Thus, the economic loss would be $\operatorname{prop}_{i}\left(c_{o}\left(z_{i}, s\right), P_{e}\right) \operatorname{Inc}_{i}\left(P_{e}\right)$, where $\operatorname{prop}_{i}\left(c_{o}\left(z_{i}, s\right), P_{e}\right)$ represents the impact function associated with the fishing sector, $c_{o}\left(z_{i}, s\right)$ denotes the contamination level in fish and $\operatorname{Inc}_{i}\left(P_{e}\right)$ represents the income from the fishing sector at the geographic unit $i$. It should be mentioned that, for this criterion, we will consider tracking points both at $1 \mathrm{~m}$ depth and at the bottom of the sea. This is justified by the presence of fish at all sea levels in this region.

The impact function $\operatorname{prop}_{i}\left(c_{o}\left(z_{i}, s\right), P_{e}\right)$, is characterised by two thresholds:

- The first one reflects the level at which responsible authorities begin to control the cesium concentration in fish before selling.

- The second one represents the level at which authorities prohibit consumption of fish caught at a given geographic unit. We shall consider the second threshold to be $500 \mathrm{~Bq} / \mathrm{kg}$ equal to the maximum allowable level of contamination for authorising fish consumption.

Between both thresholds, the impact is considered non-linear. The calibration process in section 4.1 is applicable. The only modification would be to use $\operatorname{prop}=\operatorname{prop}_{i}\left(c_{o}\right)$ in lottery $B$, reflecting the proportion of fish not allowed for sale given the level of cesium concentration $c_{o}$ in fish.

In order to evaluate the economic importance of a geographic unit, $\operatorname{Inc}\left(P_{e}\right)$, we use the same solution for the two spatial decompositions as for tourism. Thus, the annual turnover at each geographic unit is defined as:

$$
\operatorname{Inc}_{i}\left(P_{e}\right)=\sum_{j \in Z, s t: Z \cap\{i\} \neq \emptyset} \frac{S_{i j}}{\sum_{i \in U \cup Z} S_{i j}} \operatorname{Tur}_{j}\left(P_{e}\right),
$$


where $\operatorname{Tur}_{j}\left(P_{e}\right)$ refers to the turnover of fishing associated with geographic zone $j$.

We denote by $g_{P_{e}}(i, s)$, the fishing criterion rating the geographic unit $i$ under scenario $s$. Such function would be

$$
g_{P_{e}}(i, s)=\left\{\begin{array}{l}
1, \text { if } \operatorname{prop}_{i}\left(c_{o}\left(z_{i}, s\right), P_{e}\right) \operatorname{Inc} c_{i}\left(P_{e}\right) \times 97<10^{3} \\
2, \text { if } 10^{3} \leq \operatorname{prop}_{i}\left(c_{o}\left(z_{i}, s\right), P_{e}\right) \operatorname{Inc}_{i}\left(P_{e}\right) \times 97<10^{5} \\
3, \text { if } 10^{5} \leq \operatorname{prop}_{i}\left(c_{o}\left(z_{i}, s\right), P_{e}\right) \operatorname{Inc}_{i}\left(P_{e}\right) \times 97<10^{6} \\
4, \text { if } 10^{6} \leq \operatorname{prop}_{i}\left(c_{o}\left(z_{i}, s\right), P_{e}\right) \operatorname{Inc}_{i}\left(P_{e}\right) \times 97<5.10^{6} \\
5, \text { if } 5.10^{6} \leq \operatorname{prop}_{i}\left(c_{o}\left(z_{i}, s\right), P_{e}\right) \operatorname{Inc}_{i}\left(P_{e}\right) \times 97
\end{array}\right.
$$

Table 8 shows the assessment of the fishing criterion maps for the twelve scenarios. As for tourism, we can derive the economic loss in the bay, the expected loss, the relative loss and the expected income in relation with the fishing asset.

$R P_{1}$

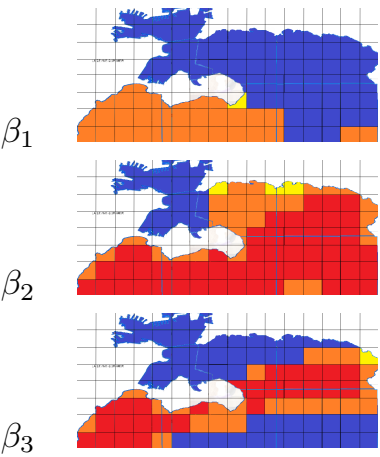

$R P_{2}$

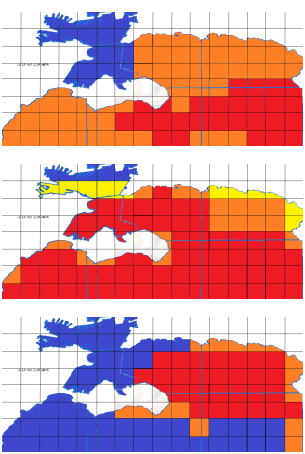

$R P_{3}$
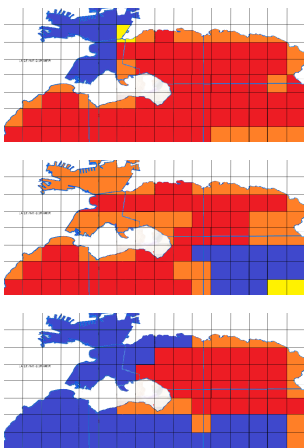

$R P_{4}$

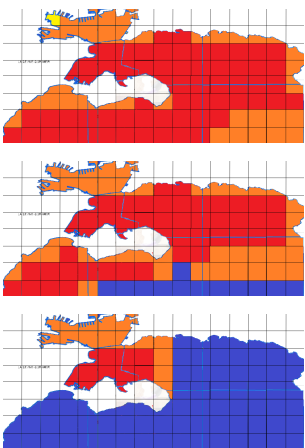

Table 8: Fishing criterion maps for the twelve scenarios

\subsection{Fish Farming}

For this criterion, as for fishing, we use the concentration level of cesium in organisms (fish and shellfish farming). Because of the special characteristics of the fish farming activity, the impact on this sector will not be assessed at a geographic unit but at the whole geographic zone 2 :

- Unlike the fishing indicator, where fish can swim through many geographic units, fish in aqua-farms cannot leave geographic zone 2 and, thus, they are just impacted by the water quality of this zone.

- The economic relevance of all geographic units in zone 2 is the same.

To assess this criterion, we consider $\overline{c_{o}(s)}=\max _{i}\left(c_{o}\left(z_{i}, s\right)\right)$, where $z_{i}$ is a geographic unit in zone 2 . The economic income associated with the fish farming sector will not be considered on the criterion evaluation, as it is the same in all geographic units of zone 2. However, this last will represent a relevant information to assess the criterion's importance during the multicriteria aggregation procedure.

We denote by $g_{F_{f}}(s)$, the fishing criterion evaluating the geographic zone 2 under scenario $s$. Such function can be interpreted as a rate representing the impact on the fish farming sector.

$$
g_{F_{f}}(s)=\left\{\begin{array}{l}
1, \text { if } \overline{c_{o}(s)}<100 \\
2, \text { if } 100 \leq \overline{c_{o}(s)}<200 \\
3, \text { if } 200 \leq \overline{c_{o}(s)}<300 \\
4, \text { if } 300 \leq \overline{c_{o}(s)}<400 \\
5, \text { if } 500 \leq \overline{c_{o}(s)}
\end{array}\right.
$$


$500 \mathrm{~Bq} / \mathrm{kg}$ and $100 \mathrm{~Bq} / \mathrm{kg}$ are respectively the maximum allowable level to consume fishes from Fukushima before and after the accident. Table 9 shows the assessment of the fish-farming criterion maps for the twelve scenarios.

\section{$R P_{1}$}

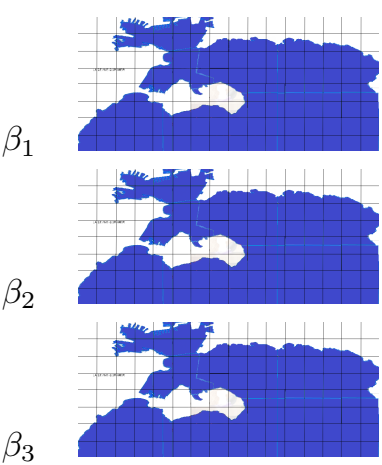

$R P_{2}$

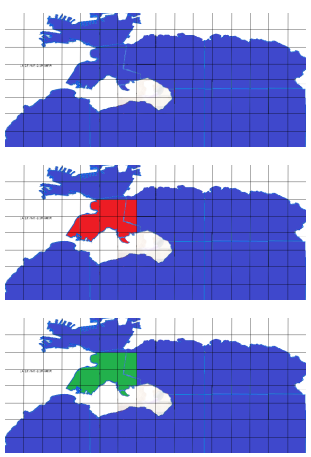

$R P_{3}$

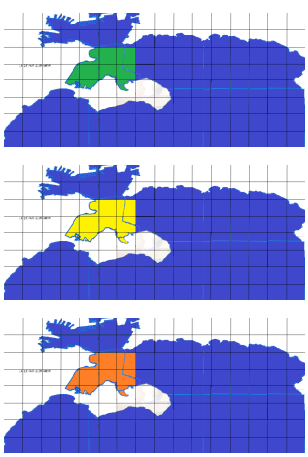

$R P_{4}$

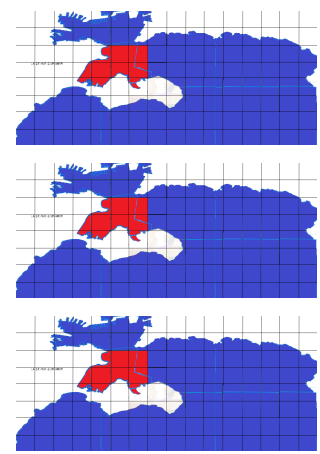

Table 9: Fish-Farming criterion maps for the twelve scenarios

\subsection{Seagrass "Posidonia Oceanica"}

We assess now a criterion function in relation with the impact of a radioactive release scenario on seagrass for each geographic unit. Unlike the previous ones, the seagrass Posidonia criterion rates the impact of a concentration level at a geographic unit level. Such impact represents a coupling between contamination levels, through the corresponding impact function, and scores associated with the presence of seagrass Posidonia at each geographic unit. To assess the corresponding impact function, we consider a Heaviside function, Figure 7 defined through

$$
\operatorname{Imp}_{i}\left(c_{w}\right)=\left\{\begin{array}{l}
0, \text { if } c_{w} \in\{1,2\} \\
1, \text { if } c_{w} \in\{3,4,5\}
\end{array}\right.
$$

where $c_{w}$ refers to the level of cesium concentration in seawater. Degrees of the presence of seagrass Posidonia are described on an ordinal scale in Table 3 . We denote by $L H p(j)$ the score associated with the degree of presence of seagrass Posidonia in geographic zone $j$, with the following scores:

- 0: Absence;

- 1: Weak presence;

- 2: Average presence;

- 3: Strong presence.

At this level, we need to solve the problem of both spatial decompositions in our problem. This asset is characterised by the lack of information about the exact distribution of seagrass Posidonia in the geographic units. Thus, we shall assume that its presence is uniform in all of them. This generates the following cases:

- For each geographic unit entirely included in a geographic zone, we consider that it has the same degree of presence of seagrass Posidonia as for the geographic zone;

- For geographic units shared between several geographic zones, we consider a weighted sum of the different degrees of presence of the seagrass in geographic zones. Weights in this work represent the relative surface at each geographic unit belonging to a given geographic zone. 
The function describing these two cases would be

$$
S c(i)=\sum_{j \in Z, s t: Z \cap\{i\} \neq \emptyset} \frac{S_{i j}}{S_{i}} L H p(j)
$$

where $S c(i)$ represents the score associated with the presence of Posidonia at zone $i, S_{i j}$ the surface (land excluded) of the geographic zone $j$ and geographic unit $i$ and $S_{i}$ the surface of geographic unit $i$. We denote by $R S c(i)$, the rounded value of $S c(i)$. We denote by $g_{S p}(i, s)$, the seagrass Posidonia criterion rating the geographic unit $i$, under scenario $s$

$$
g_{S p}\left(i,\left(\beta_{k}, z_{R} P_{j}\right)\right)=\operatorname{Imp}_{i}\left(z_{i}, c_{w}\left(\left(\beta_{k}, R P_{j}\right), S p\right)\right) R S c(i)+1 .
$$

Table 10 shows the assessment of the seagrass Posidonia criterion for the twelve scenarios.

$R P_{1}$

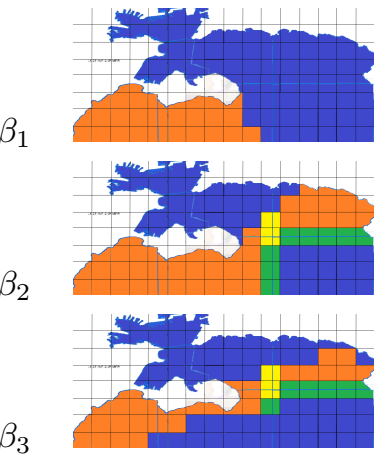

$R P_{2}$

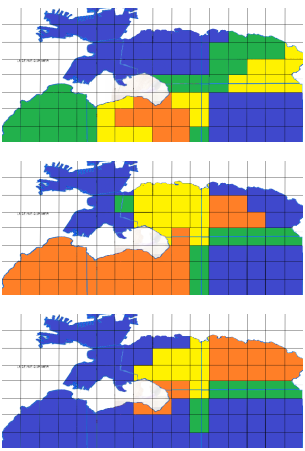

$R P_{3}$
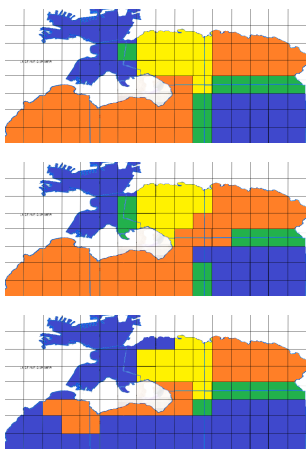

$R P_{4}$

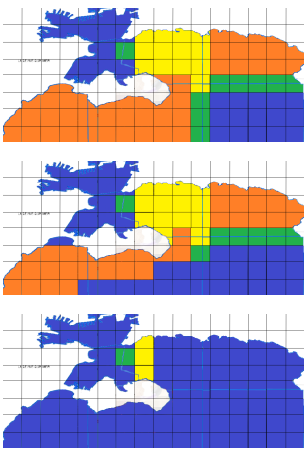

Table 10: Seagrass-Posidonia criterion maps for the twelve scenarios

Again, we could compute various aggregated indices.

\section{Multiple impacts}

We finally consider the case with multiple criteria. Recall that for each scenario $\left(\beta_{i}, R P_{j}\right)$, which occurs with probability $p_{i j}=q_{i} \times r_{j}$, we obtain four criterion maps:

- Fishing: $g_{P_{e}}\left(\beta_{i}, R P_{j}\right)$

- Fish farming: $g_{F_{f}}\left(\beta_{i}, R P_{j}\right)$

- Seagrass Posidonia: $g_{S_{p}}\left(\beta_{i}, R P_{j}\right)$

- Tourism: $g_{T}\left(\beta_{i}, R P_{j}\right)$

The aim of this section is to aggregate effects due to:

- multiple criteria.

- uncertainty.

In the first part of this section, we shall solve the multiple criteria problem. In the second part, we aggregate uncertainties by considering scenarios as criteria evaluating the geographic units in the aggregated maps with respect to their corresponding importance (probabilities). 


\subsection{ELECTRE-TRI for multiple criteria aggregation}

The problem at hand is a rating one. To solve it we use the ELECTRE TRI method. The first step consists of rating each geographic unit $X$ for each scenario $\left(\beta_{i}, R P_{j}\right)$ :

$$
X\left(\beta_{i}, R P_{j}\right)=\left(g_{P_{e}}\left(\beta_{i}, R P_{j}\right), g_{F_{f}}\left(\beta_{i}, R P_{j}\right), g_{S_{p}}\left(\beta_{i}, R P_{j}\right), g_{T}\left(\beta_{i}, R P_{j}\right)\right) .
$$

We consider the following notation:

- the set of criteria $\mathcal{F}$, with criteria $\mathcal{F}_{j}$ characterised by an importance (weight) $w_{j}$.

- the set $\mathcal{C}$ of predefined impact categories. Each category $\mathcal{C}_{k}$ is characterised by a lower bound, called limiting profile, which we denote $r^{k}=\left(r_{j}^{k}\right)_{k \in \mathcal{F}}$.

The idea is, then, to compare the performance of each geographic unit with the limiting profiles to assign it to the corresponding category. Figure 12 illustrates the issue where the axes represent the criteria and we aim to assign $x$, a geographic unit, to one of the five predefined categories by comparing it with the limiting profiles.

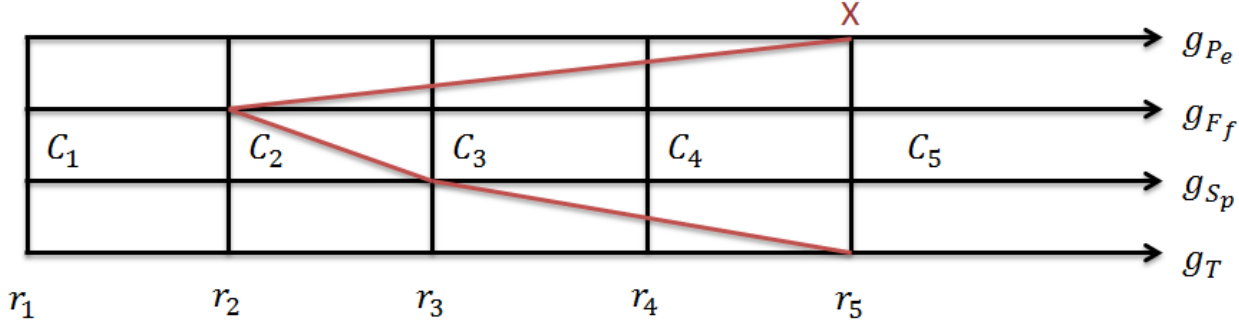

Figure 12: Illustration of the multiple criteria problem

\subsubsection{Assessing criteria weights}

The literature reports several methods for assessing ELECTRE-TRI parameters from assignment examples, [7, 14], 15], 17, 20. We use a simplified version of the optimisation model in [15], by assuming that we are able to assess, with the aid of the decision maker, the limiting profiles. We denote by $A=\left\{A_{1}, \ldots, A_{5}\right\}$ the learning set where the assignments are previously known, with $A_{k}=\left\{a_{k i} ; a_{k i} \in \mathcal{C}_{k}\right\}$. The learning set consists on assignment examples: examples of performance vectors, for which the rating is previously known.

Under the previous assumption, and based on the majority rule, an alternative $a_{k} \in A_{k}$ from the learning set is assigned to category $\mathcal{C}_{k}$ if there is a weighted-majority of criteria in favour of " $a_{k}$ is at least as good as the limiting profile $r^{k}$ " and there is no weighted-majority in favour of " $a_{k}$ is at least as good as the limiting profile $r^{k+1} "$. This can be written as

$$
\sum_{j \in \mathcal{F}, g_{j}\left(a_{k i}\right) \geq r_{j}^{k}} w_{j} \geq c,
$$

and

$$
\sum_{j \in \mathcal{F}, g_{j}\left(a_{k i}\right) \geq r_{j}^{k+1}} w_{j}<c,
$$

where $\mathrm{c}$ is the concordance threshold. Such inequalities are equivalent to the following equalities, introducing the slack variables $x_{k i}$ and $y_{k i}$ :

$$
\sum_{j \in \mathcal{F}, g_{j}\left(a_{k i}\right) \geq r_{j}^{k}} w_{j}-x_{k}=c
$$


and

$$
\sum_{j \in \mathcal{F}, g_{j}\left(a_{k i}\right) \geq r_{j}^{k+1}} w_{j}+y_{k}=c .
$$

If the slack variables $x_{k i}$ and $y_{k i}$ are positive, the assignment made by the decision maker corresponds to the assignment done through the pessimistic procedure of ELECTRE TRI: the lower the minimum of these values, the less adapted is the model. In case one of these slack variables is negative, the concordance principle is not sufficient to justify the assignment and we need to assess the veto threshold. Thus, we need to maximise the minimum of both slack variables to take into account the worst assignment from the decision maker through

$$
\max \min _{\substack{a_{k i} \in A_{k} \\ A_{k} \in A}}\left(x_{k i}, y_{k i}\right)
$$

and we also need to maximise the ability of the model to assign alternatives correctly through

$$
\max \sum_{\substack{a_{k i} \in A_{k} \\ A_{k} \in A}}\left(x_{k i}+y_{k i}\right) .
$$

We then consider the following decision variables:

- Weight vector. $w_{j}, \forall j \in \mathcal{F}$

- Concordance threshold $c$

- Slack variables $x_{k i}, y_{k i}, \forall a_{k i} \in A_{k}, \forall k$

and the following objective function to be maximised

$$
\operatorname{maximise}\left(\min _{\substack{a_{k i} \in A_{k} \\ A_{k} \in A}}\left(x_{k i}, y_{k i}\right)+\epsilon \sum_{\substack{a_{k i} \in A_{k} \\ A_{k} \in A}}\left(x_{k i}+y_{k i}\right)\right)
$$

Problem (1) is equivalent to

$$
\begin{array}{ll}
\operatorname{maximise} & \delta+\epsilon \sum_{\substack{a_{k i} \in A_{k} \\
A_{k} \in A}}\left(x_{k i}+y_{k i}\right) \\
\text { s.t } & \delta \leq x_{k i}, \forall a_{k i} \in A_{k}, \forall A_{k} \in A \\
& \delta \leq y_{k i}, \forall a_{k i} \in A_{k}, \forall A_{k} \in A .
\end{array}
$$

In order to assess criteria weights, we add to the previous model the following constraints:

- Two constraints related with the slack variables $\forall a_{k i} \in A_{k}, \forall A_{k} \in A, \sum_{\substack{j \in \mathcal{F} \\ g_{j}\left(a_{k i}\right) \geq r_{j}}} w_{j}-x_{k i}=c$ and $\sum_{\substack{j \in \mathcal{F} \\ g_{j}\left(a_{k i}\right) \geq r_{j}^{k+1}}} w_{j}+y_{k i}=c$

- The majority constraint related to the concordance principle $c>0.5$.

- We assume that all criteria are relevant, $w_{j}<c, \forall j \in \mathcal{F}$.

- The strict positivity and normalisation of weights: we respectively have $\forall j \in \mathcal{F}, w_{j}>0$ and $\sum_{j} w_{j}=1$. 
We finally use the following model:

$$
\begin{array}{ll}
\text { maximise } & \delta+\epsilon \sum_{\substack{a_{k i} \in A_{k} \\
A_{k} \in A}}\left(x_{k i}+y_{k i}\right) \\
\text { s.t } \quad & \delta \leq x_{k i}, \forall a_{k i} \in A_{k}, \forall A_{k} \in A, \\
& \delta \leq y_{k i}, \forall a_{k i} \in A_{k}, \forall A_{k} \in A, \\
& \sum_{\substack{j \in \mathcal{F} \\
g_{j}\left(a_{k i}\right) \geq r_{j}^{k}}} w_{j}-x_{k i}=c, \forall a_{k i} \in A_{k}, \forall A_{k} \in A, \\
& \sum_{j \in \mathcal{F}} w_{j}+y_{k i}=c, \forall a_{k i} \in A_{k}, \forall A_{k} \in A, \\
& \sum_{j}\left(a_{k i}\right) \geq r_{j}^{k+1} \\
& \sum_{j} w_{j}=1, \\
& w_{j}<c, \forall j \in \mathcal{F}, \\
& w_{j}>0, \forall j \in \mathcal{F}, \\
& 0.5<c<1 .
\end{array}
$$

Example: We consider the following learning sets:

$$
\begin{aligned}
& A_{2}=\{(1,3,2,1),(1,2,3,1),(3,1,1,1)\} \\
& A_{3}=\{(2,4,3,3),(4,2,3,2),(3,3,2,4)\} \\
& A_{4}=\{(2,4,4,5),(4,4,4,3),(5,5,3,3)\} \\
& A_{5}=\{(5,4,4,5),(5,4,5,3),(3,3,5,5)\}
\end{aligned}
$$

The limiting profile of a category $\mathcal{C}_{k}$ is the vector $(k, k, k, k)$. Therefore, we will not consider a learning set associated with category $\mathcal{C}_{1}$ (no impact), since it does not provide us with any relevant information. A profile in $A_{1}$ will always dominate $(1,1,1,1)$; based on the majority principle it will always be outranked by $(2,2,2,2)$, otherwise it will not be assigned to $\mathcal{C}_{1}$. Hence, both $x_{1}$ and $y_{1}$ are positive.

The tourism and fishing sectors are more sensitive than that of fish farming since they are present in most of the geographic units. Hence, we consider two additional constraints, $w_{1} \geq w_{2}$ and $w_{4} \geq w_{2}$.

The solution of the model $(2)$ is:

- weights: $w_{1}=0.33 ; w_{2}=0.1 ; w_{3}=0.23 ; w_{4}=0.34$

- concordance threshold: $c=0.54$;

- the slack variables:

- slacks associated with $A_{2}=\{(1,3,2,1),(1,2,3,1),(3,1,1,1)\}$ are $\left(x_{21}=-0.17, y_{21}=0.41\right)$, $\left(x_{22}=-0.07, y_{22}=0.17\right),\left(x_{23}=-0.17, y_{23}=0.17\right)$;

- slacks associated with $A_{3}=\{(2,4,3,3),(4,2,3,2),(3,3,2,4)\}$ are $\left(x_{31}=0.15, y_{31}=0.41\right),\left(x_{32}=\right.$ $\left.0.35, y_{32}=0.17\right),\left(x_{33}=0.25, y_{33}=0.17\right)$;

- slacks associated with $A_{4}=\{(2,4,4,5),(4,4,4,3),(5,5,3,3)\}$ are $\left(x_{41}=0,15, y_{41}=0.17\right),\left(x_{42}=\right.$ $\left.0.15, y_{42}=0.51\right),\left(x_{43}=-0.7, y_{43}=0.07\right)$;

- slacks associated with $A_{5}=\{(5,4,4,5),(5,4,5,3),(3,3,5,5)\}$ are $x_{51}=0.15, x_{52}=0.05, x_{53}=$ 0.05 . 
Negative slack variables can be justified due to the non consideration of the veto threshold in our linear model. For example, vector $(1,3,2,1)$, using the majority principle, should be assigned to category $\mathcal{C}_{1}$, since $w_{1}+w_{4}>c$. However, $(1,3,2,1)$ is assigned to 2 because of its performance (a rate 3 ) under the fish farming criterion, and thus we cannot consider that there is no considerable impact. A similar remark is valid for $(1,2,3,1),(3,1,1,1)$ and $(5,5,3,3)$. Based on an observation over assignment examples with negative slack variables, a threshold value equal to 2 is the minimum value justifying the assignments.

\subsubsection{Assignment zones to the predefined categories}

We show now the results of the multiple criteria aggregation procedure using ELECTRE-TRI. The parameters we use are derived from the example in Section 5.1 .1

- criteria weights: $w_{1}=0.33 ; w_{2}=0.1 ; w_{3}=0.23 ; w_{4}=0.34$;

- concordance threshold: $c=0.54$;

- veto threshold $v=2$;

In what follows, we display the criteria-maps associated with the scenarios ( $\mathrm{Mistral}, R \mathrm{P}_{3}$ ), and the corresponding aggregated map.

\section{Scenario (Mistral, $R P_{3}$ )}

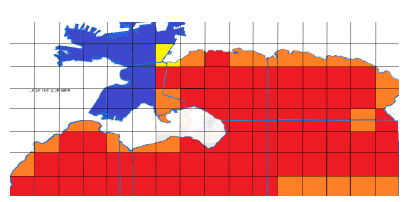

Fishing

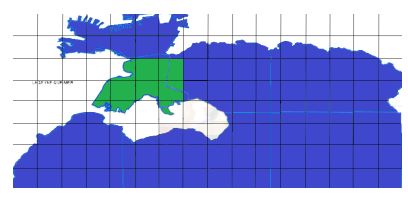

Fish Farming

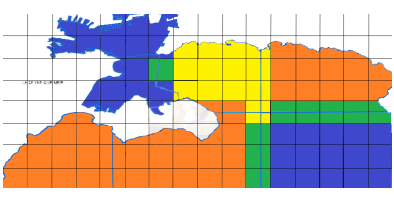

Seagrass Posidonia

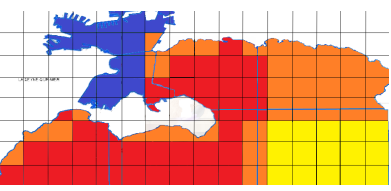

Tourism

Figure 13: Criteria maps for the (mistral, $\left.R P_{3}\right)$

These maps display the criteria for fishing, fish farming, seagrass Posidonia and tourism, respectively. They are assessed based on the level of cesium concentration, from 1 to 5, where level 1 refers to low concentration and level 5 to a high concentration, and the vulnerability of each geographic unit from a given asset point of view. For example, zones 1 and 2 are not very impacted because of a low level of concentration; however, zone 3 is characterised by a level 5 of cesium concentration, crossed with important tourist and fishing activities, an average presence of seagrass Posidonia and no activity of fish farming. Thus, the outcome of the multiple criteria aggregation mostly associate a rate 1 to geographic units in zones 1 and 2 and a rate 5 in zone 3 (recall that $w_{1}+w_{4}=0.67>0.54$ and there is no discordance). The result of the aggregation is displayed in Figure 14

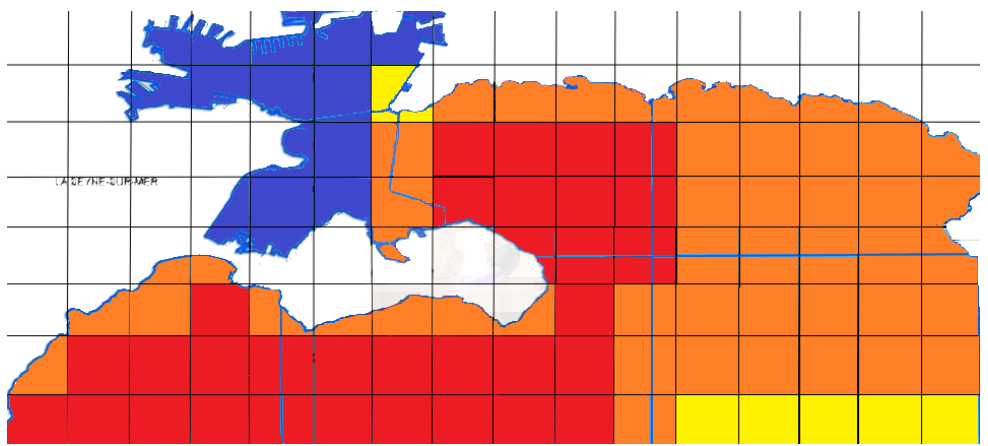

Figure 14: The aggregated map for (mistral, $\left.R P_{3}\right)$ scenario 


\subsection{Uncertainty aggregation}

The aim of this section is to model uncertainties represented through different accident scenarios. We need to establish a global rate for geographic units. We can aggregate the impact induced by different scenarios either before aggregating criteria or after the aggregation. The most common technique synthesising uncertainties is to compute expected values. We used the expected impact in section 4 , before the multiple criteria aggregation procedure, in order to evaluate the sensitivity of each geographic unit from a single criterion point of view. In this section, we deal with the case in which we want to synthesize uncertainties related with the accident scenarios after the multiple criteria aggregation, section 5.1 .

Computing the expected impact at each geographic unit allows for compensation between rates with respect to the probabilities over scenarios. In our context, such compensation is not desirable since the performance of geographic units under each scenario is modeled through rates. The aggregation procedure proposed in this section is based on the concordance and discordance principles, reflected in ELECTRE TRI, and can be solved as any multiple criteria rating problem, by considering scenarios as criteria, probabilities as weights and geographic units as alternatives to be evaluated.

\subsubsection{Probabilities and ELECTRE TRI parameters}

In this section, we assess uncertainties over the initial conditions and the ELECTRE TRI parameters to rate the geographic units. In section 2.2.1 we defined three sea conditions, corresponding to different types of wind. In what follows, we associate to the types of wind the following probabilities [8]: For mistral $q_{1}=0.4$, for east wind $q_{2}=0.4$ and for steady wind $q_{3}=0.2$.

To assess probabilities over the four release positions, we assume that the closer we are to the naval base, the greater the probability of a release. Such hypothesis can be transcribed through the following inequalities $r_{i}>r_{j}$ where $i>j$, with $r_{i}>0, \sum_{i=1}^{4} r_{i}=1$. One possible assessment would be $r_{1}=0.5, r_{2}=$ $0.25, r_{3}=0.15$ and $r_{4}=0.1$, which we use in our initial analysis.

In what follows, we shall assume such values. A sensitivity analysis with respect to them, based on intervals, would be necessary, but we shall not include it in this paper. Observe now that this "multiple criteria decision making problem" is characterised by:

- The criteria evaluating the geographic units: the release scenarios;

- The weights of criteria: the probabilities $p_{i j}=q_{i} \times r_{j}$;

- Under each scenario, impacts on geographic units are rated from 1 to 5 . We shall consider the same scale for the aggregated rate;

- The veto threshold: $v=2$.

\subsubsection{Results of the aggregation}

We represent now the results of the aggregation over the 12 scenarios using ELECTRE TRI and the parameters in section 5.2 .1 .

From Table 11, we notice that for the release position $R P_{1}$, the geographic zone 5 is highly impacted. This is justified by the simulated release position in Zone 5 , and the high importance of economic environmental assets in this area. This remark is still valid for Zones 3 and 6 for $R P_{2}$ and 3 and 4 for $R P_{3}$. depending on the direction of wind, other zones might be highly impacted. For instance, considering the scenarios characterised by a Steady wind, the impacted zones are those close to the release position. We also note from Table 11 that the most impacting scenarios are those corresponding to East wind. The main reason is the high dispersion of radionuclides in the majority of geographic zones due to the sea currents, which impact many assets.

Zone 1 where the simulated $R P_{4}$ took place is highly impacted, rated 4 , but less impacted than other neighbouring zones, even if the contamination level is the highest. This is due to several reasons, such as the non presence of seagrass Posidonia and fish farming activity, representing a total weight $w_{2}+w_{3}=0.33$, the low income from fishing activity compared to the other geographic zones 
$R P_{1}$
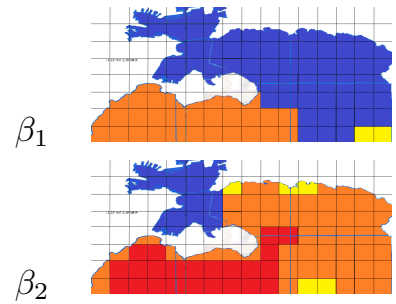

$\beta_{2}$

$\beta_{3}$
$R P_{2}$
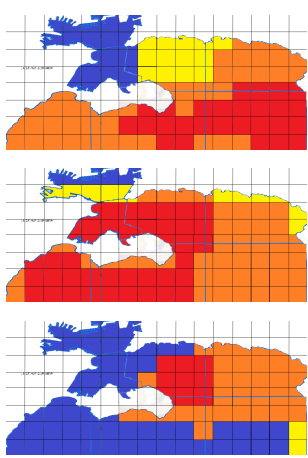

$R P_{3}$
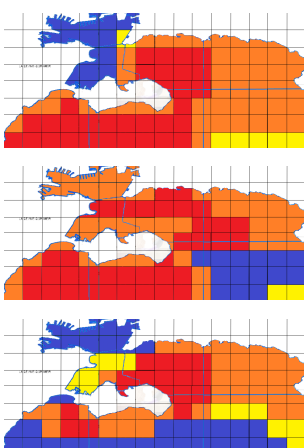

$R P_{4}$

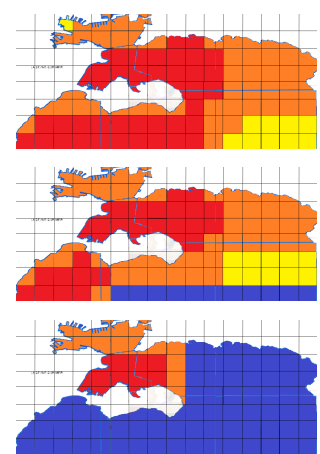

Table 11: The aggregated maps for the twelve scenarios

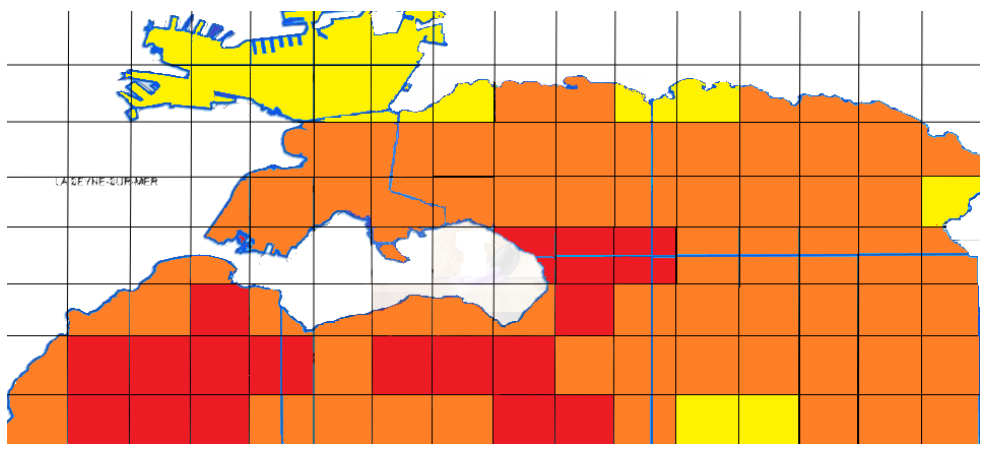

Figure 15: The aggregated map for the 12 release scenarios

Aggregating the release scenarios, we note from Figure 15 that geographic zone 1 seems the less impacted. The reason of such level of impact in zone 1 is justified by the low presence or absence of the majority of assets and the low level of concentration at several release scenarios. The other geographic zones are either rated 4 or 5 , since scenarios corresponding to East wind, occurring with a probability of 0.4 , impact highly the majority of the Bay and scenarios $R P_{2}, R P_{3}$ and $R P_{4}$ in the case of Mistral type of wind, occurring with a total probability of 0.2 , impact highly zones $3,4,5,6$ and 7 .

\section{Discussion}

For the typical reasons related to a real world application we were induced to make a number of simplification hypotheses which we discuss here. Clearly these also indicate relevant research directions to explore.

\subsection{Analysis of the multiple criteria aggregation procedures}

The multiple criteria aggregation procedure used in this paper is based upon the concordance and non discordance principles. The obtained results are coherent. Nevertheless, the use of ELECTRE TRI method might lead to inconsistent results. For instance, let us consider the impact vector $(5,1,1,3)$ characterizing the geographic units in zone 7 in case of scenario (Mistral, $R P_{3}$ ). Because of the discordance principle $(5,1,1,3)$ will be rated 4 . Let us consider a fictitious geographic unit characterized by $(4,3,3,3)$, using the 
same parameters, this last will be rated 3 . However, $(5,1,1,3)$ is strictly preferred to $(4,3,3,3)$. Other inconsistencies, might come from Condorcet Paradox due to the concordance principle.

\subsection{Evaluating a map}

A relevant question for the decision maker can be, how can we rate a geographic area? The answer to this question is not simple. The rate of a geographic space depends upon:

- the characteristics of the problem, e.g. we may have interactions between geographic units (or not) [16];

- the aggregation path, e.g. one possible path is aggregating the multiple criteria problem, then synthesising uncertainties before rating the global map. Changing this order may lead to a different result.

In this work, the interaction effects between geographic units is not taken into account because, in all simulations, geographic units belonging to the same category of impact are grouped together.

\section{Conclusion}

We have presented an approach to assess spatial risks, in cases characterised by the presence of several assets, spatial characteristics and uncertainties over the accident parameters (mainly the release position and sea currents). The developed approach is illustrated through an application of nuclear releases in the marine environment. The methodology aims to assess the impact of a nuclear accident at a geographic space (in our case the Bay of Toulon) as part of a post-accident analysis. In order to evaluate the impact of a nuclear release on a geographic space, several methods were used for decision aiding purposes. The procedure developed consists of representing uncertainties through accident scenarios, structuring impact indices for each asset and under each scenario, and synthesising these indices using a multiple criteria aggregation procedure, describing the general impact over the studied area. We then aggregated uncertainties to evaluate the vulnerability of the studied area regarding the accident scenarios. At a next step, we shall establish a robustness analysis and study the possible recommendations to one or several decision markers, depending on their risk aversion.

\section{Acknowledgment}

The authors would like to thank the "Agence Nationale de la Recherche" (ANR) project AMORAD for supporting this work and the COST-action IS1304 for supporting a short term scientific mission at the "Instituto de Ciencias Matematicas" (ICMAT) on expert judgment.

\section{Appendix 1. The hydrodynamic model}

\subsection{The advection diffusion equation}

To assess the radiological impact of an accidental release in seawater, the IRSN has developed a hydrodynamic model tool called STERNE (Simulation du Transport et du transfert d'Eléments Radioactifs dans l'environNEment marin, translated as Simulation of radionuclide transport and transfer in marine environments) to simulate the dispersion of radionuclides in the marine area. This tool is based on the tracer advection diffusion equation estimating the dispersion of radionuclides:

$$
\frac{\partial C}{\partial t}-\frac{\partial}{\partial x}\left[D_{x} \frac{\partial c}{\partial x}-u_{x} c\right]-\frac{\partial}{\partial y}\left[D_{y} \frac{\partial c}{\partial y}-u_{y} c\right]-\frac{\partial}{\partial z}\left[D_{z} \frac{\partial c}{\partial z}-u_{z} c\right]=F(c, t)
$$

\section{where $C$ is the radionuclide concentration; $u$, the advection current; and, finally, $D$ is the turbulent diffusion} tensor. The model is illustrated with Figure 16

Since it is difficult to solve this equation analytically, the most common procedure consists of discretising time, the choice of time step depending on the mesh size and maximum sea current velocity for the area considered and sigma-coordinates and calculates this concentration at each grid point and time step. This model takes into account the half life of each radionuclide considered. 


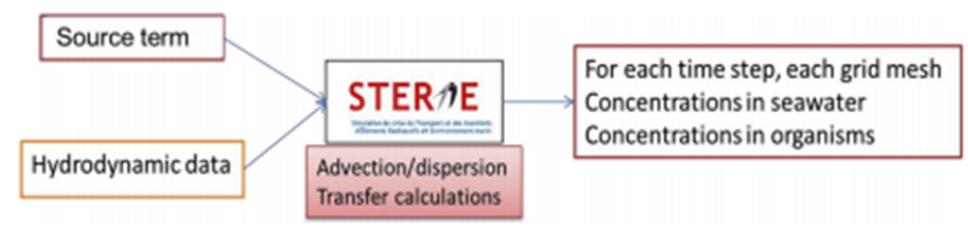

Figure 16: Schematic diagram of STERNE implementation principle

\subsection{Input data}

For each time step and mesh, the hydrodynamic data required as input to dispersion calculations includes

- The cumulative water fluxes in $x, y$ and $z$ directions; free surface elevation and diffusion coefficients (set to calculate the exact quantity of water passing through the grid meshes at each instant and should satisfy the continuity equation)

- The free surface elevation and diffusion coefficients.

Hydrodynamic models are generated based on hindcasts and forecasts of meteorological and tidal forcing. Source terms are characterised by:

- known quantities of radionuclide releases.

- known localisations (Release point coordinates).

- instants of releases.

\section{Appendix 2. Brief introduction of ELECTRE TRI}

ELECTRE TRI is a rating method, aiming to assign elements of a set $A$ to one of predefined ordered categories $C_{1}, \ldots, C_{p}$. Such categories are ranked from the worst to the best: $C_{h+1} \gg C_{h} \forall h \in\{1, \ldots, p-1\}$ where $\gg$ refers to a complete order on the set of categories, [19. This method uses a majority rule while respecting a minority using a veto rule, in order to compare elements of a set $A$ (representing actions) to the profiles characterising categories. Let us denote $r_{1}, \ldots, r_{p}$ the limiting profiles characterising the $p$ categories, $r_{k}$ refers to the upper limit of category $C_{k}$ and the lower limit of category $C_{k+1}, k=1,2, \ldots, p$ and $R$ the set of the associate indices. Let $F$ denote the set of the indices of the criteria $g_{1}, g_{2}, \ldots, g_{m}$. Without loss of generality, we make the assumption that preferences increase with the value on each criterion. ELECTRE TRI is based on an outranking relation $S$. Roughly speaking, an outranking relation can be interpreted as, "at least as good as". In a first step, we aim at constructing an outranking relation $S$ characterising how actions compare to each limiting profile. Thus, we use $S$ to assign each action to a specific category. The procedure can be described as follows:

- Partial concordance index $c_{j}\left(a, r_{h}\right) \in[0,1], \forall j \in F h \in R$ : IT represents a weight of the proposition $a$ is at least as good as a certain $r_{h}$ from the criterion $j$ point of view. The formulation of partial concordance index is:

$$
c_{j}\left(a, r_{h}\right)=\left\{\begin{array}{l}
1, \text { if } g_{j}\left(r_{h}\right)-g_{j}(a) \leq 0 \\
0, \text { if } g_{j}\left(r_{h}\right)-g_{j}(a)>0
\end{array}\right.
$$

This index takes 1 to denote a full approval of the proposition " $a$ is at least as good as $r_{h}$ " from the criterion $j$ point of view. 
- Global concordance index $c\left(a, r_{h}\right) \in[0,1], \forall h \in R$ : represents the majority rule, i.e. the global weight of all criteria approving the proposition " $a$ is at least as good as $r_{h}$ ".

$$
c\left(a, r_{h}\right)=\frac{\sum_{j \in F} w_{j} c_{j}\left(a, r_{h}\right)}{\sum_{j \in F} w_{j}}
$$

where $w_{j}, j \in F$ refers to the weight associated to the criterion $j$.

- Discordance index $d_{j}\left(a, r_{h}\right) \in[0,1], \forall j \in F h \in R$ : represent the respect of minority rule, i.e. when the difference between a certain $r_{h}$ and a for a given criterion $j$ is greater than a threshold, called veto threshold, the outranking relation between $a$ and $r_{h}$ is vetoed.

$$
d_{j}\left(a, r_{h}\right)=\left\{\begin{array}{l}
1, \text { if } g_{j}\left(r_{h}\right)-v_{j}\left(r_{h}\right) \geq g_{j}(a) \\
0, \text { otherwise }
\end{array}\right.
$$

where $v_{j}\left(r_{h}\right), j \in F, h \in R$ refers to the veto threshold associated with the criterion $j$.

- Credibility index or the outranking relation $\sigma\left(a, r_{h}\right)$ aggregating the concordance and the discordance.

In the ELECTRE TRI method, the assignment of $a$ depends on the values of $\sigma\left(a, r_{h}\right), \sigma\left(r_{h}, a\right)$ and a cutting threshold $\lambda$. When $\sigma\left(a, r_{h}\right) \geq \lambda$, a outranks $r_{h}$, denoted $a S r_{h}$. Four possible situation may occur:

- $\sigma\left(a, r_{h}\right) \geq \lambda, \sigma\left(r_{h}, a\right) \geq \lambda \Longrightarrow a I r_{h}$, i.e. $a$ is indifferent to $r_{h}$

- $\sigma\left(a, r_{h}\right)<\lambda, \sigma\left(r_{h}, a\right)<\lambda \Longrightarrow a R r_{h}$, i.e. $a$ is incomparable to $r_{h}$

- $\sigma\left(a, r_{h}\right) \geq \lambda, \sigma\left(r_{h}, a\right)<\lambda \Longrightarrow a P r_{h}$, i.e. $a$ is preferred to $r_{h}$

- $\sigma\left(a, r_{h}\right)<\lambda, \sigma\left(r_{h}, a\right) \geq \lambda \Longrightarrow r_{h} P a$, i.e. $r_{h}$ is preferred to $a$

The assignment is done using two procedures:

- Pessimistic (conjunctive) procedure. It consists on the pairwise comparaison between each action $a$ and the limiting profil $r_{h}$ starting from $h=p$ to $h=0$. We stop this procedure when $a S r_{h}$, and potentially $a$ will be assigned to $C_{h+1}$.

- Optimistic (disjunctive) procedure. We compare each action $a$ and the limiting profil $r_{h}$ starting from $h=1$ to $h=p$. We stop this procedure when $r_{h} S a$, and potentially $a$ will be assigned to $C_{h}$.

The imperfection of knowledge about evaluations of criteria can be taken into account when defining the thresholds of the aggregation model. However, it is not easy for the decision maker to provide precise and complete information about weights and thresholds. Numerous technics were proposed in the literature to elicit these parameters, [7, [14, [15], [17], 20].

\section{References}

[1] M. Aoyama and K. Hirose. Temporal variation of 137 cs water column inventory in the North Pacific since the 1960s. Journal of environmental radioactivity, 69(1):107-117, 2003.

[2] M. Aoyama, K. Hirose, T. Miyao, Y. Igarashi, and P. Povinec. 137cs activity in surface water in the western North Pacific. Journal of Radioanalytical and Nuclear Chemistry, 248(3):789-793, 2001.

[3] M. Aoyama, D. Tsumune, and Y. Hamajima. Distribution of 137cs and 134cs in the North Pacific Ocean: impacts of the TEPCO Fukushima-Daiichi NPP accident. Journal of Radioanalytical and Nuclear Chemistry, 296(1):535-539, 2013.

[4] D. Bouyssou, Th. Marchant, M. Pirlot, A. Tsoukiàs, and Ph. Vincke. Evaluation and decision models with multiple criteria: Stepping stones for the analyst. Springer Verlag, Boston, 1st edition, 2006.

[5] S. Bussotti, P. Guidetti, and G. Matricardi. Morphological analysis of Posidonia oceanica flowers from a reef formation and a shallow water meadow of the Ligurian Sea (north-western Mediterranean). Vie et milieu, 48(1):55-62, 1998.

[6] J.M. Devaud, G. Groussaud, and E. Jacquet-Lagreze. UTADIS: Une methode de construction de fonctions d'utilite additives rendant compte de jugements globaux. In European working group on MCDA, Bochum, Germany, 1980. 
[7] L. Dias, V. Mousseau, J. Figueira, and J. Clímaco. An aggregation/disaggregation approach to obtain robust conclusions with ELECTRE TRI. European Journal of Operational Research, 138(2):332-348, 2002

[8] C. Dufresne, C. Duffa, and V. Rey. Wind-forced circulation model and water exchanges through the channel in the Bay of Toulon. Ocean Dynamics, 64(2):209-224, 2014.

[9] C. Estournel, E. Bosc, M. Bocquet, C. Ulses, P. Marsaleix, V. Winiarek, I. Osvath, C. Nguyen, T. Duhaut, F. Lyard, et al. Assessment of the amount of cesium-137 released into the Pacific Ocean after the Fukushima accident and analysis of its dispersion in Japanese coastal waters. Journal of Geophysical Research: Oceans, 117(C11), 2012.

[10] P. H. Farquhar. State of the art: utility assessment methods. Management science, 30(11):1283-1300, 1984.

[11] M. C. Gambi, M. Lorenti, G. F. Russo, M. B. Scipione, and V. Zupo. Depth and seasonal distribution of some groups of the vagile fauna of the Posidonia oceanica leaf stratum: structural and trophic analyses. Marine Ecology, 13(1):17-39, 1992.

[12] E. Jacquet-Lagrèze and Y. Siskos. Assessing a set of additive utility functions for multicriteria decision making: the UTA method. European Journal of Operational Research, 10:151-164, 1982.

[13] P. Le Hir, R. S. Jacinto, B. Thouvenin, L. Guézennec, Ph. Bassoullet, Ph. Cugier, F. Leboulenger, R. Hocdé, P. Lesueur, and L. Romaña. Courants, vagues et marées(les mouvements de l'eau). Programme scientifique Seine-aval, 2001.

[14] V. Mousseau. Eliciting information concerning the relative importance of criteria. In Advances in multicriteria analysis, pages 17-43. Springer, 1995.

[15] V. Mousseau and R. Slowinski. Inferring an ELECTRE TRI model from assignment examples. Journal of global optimization, 12(2):157-174, 1998.

[16] S. A. M. Takougang, V. Brison, and M. Pirlot. Two models for comparing decisional maps. International Journal of Multicriteria Decision Making 73-74, 3(2-3):129-156, 2013.

[17] T. Tervonen, J. Figueira, R. Lahdelma, and P. Salminen. An inverse approach for ELECTRE III. Instituto de Engenharia de Sistemas e Computadores de Coimbra, 2004.

[18] A. Tsoukiàs. On the concept of decision aiding process. Annals of Operations Research, 154:3 - 27, 2007.

[19] W. Yu. Aide multicritère à la décision dans le cadre de la problématique du tri: Concepts, méthodes et applications. PhD thesis, Paris 9, 1992.

[20] J. Zheng, S. A. M. Takougang, V. Mousseau, and M. Pirlot. Learning criteria weights of an optimistic Electre Tri sorting rule. Computers \&5 Operations Research, 49:28-40, 2014. 